Supporting Information

\title{
Structural Properties and Catalytic Implications of the SPASM Domain Iron-Sulfur Clusters in Methylorubrum extorquens PqqE
}

Wen Zhu†, Lindsey M. Walker ${ }^{\ddagger}$ Lizhi Tao ${ }^{\S}$, Anthony T. Iavarone ${ }^{\dagger}$, Xuetong Weill, R. David Britt ${ }^{\S}$, Sean J. Elliott**, and Judith P. Klinman ${ }^{\dagger 1 \perp *}$

$\uparrow$ California Institute for Quantitative Biosciences, University of California-Berkeley, Berkeley, California 94720, United States

¥ Department of Chemistry, Boston University, Boston, Massachusetts 02215, United States

$\S$ Department of Chemistry, University of California-Davis, Davis, California 95616, United States

" Department of Molecular and Cell Biology, University of California-Berkeley, Berkeley, California 94720, United States

${ }^{\perp}$ Department of Chemistry, University of California-Berkeley, Berkeley, California 94720, United States

*Corresponding authors: klinman@berkeley.edu, elliott@bu.edu 


\section{Table of Contents}

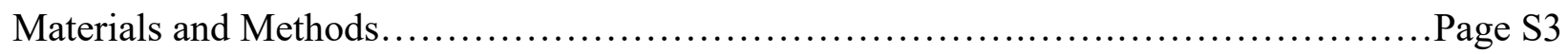

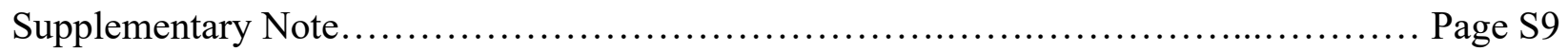

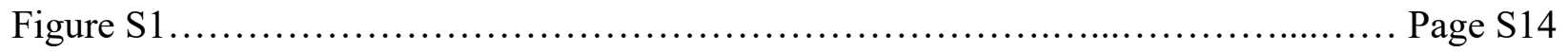

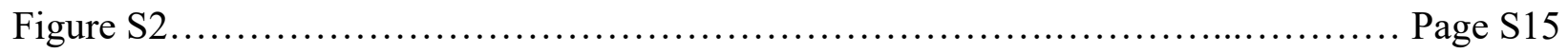

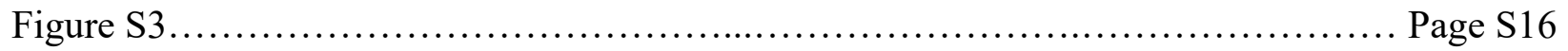

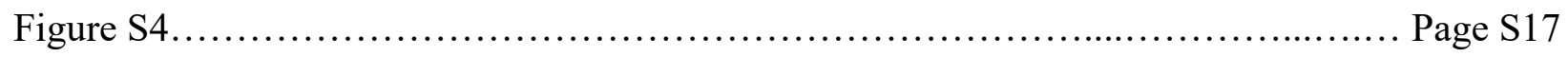

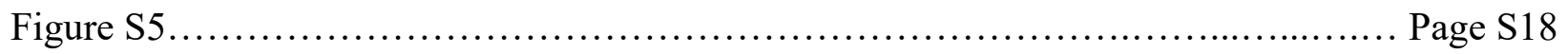

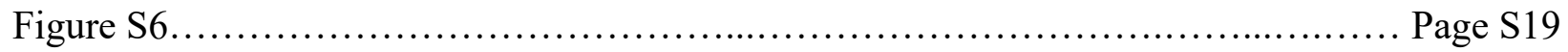

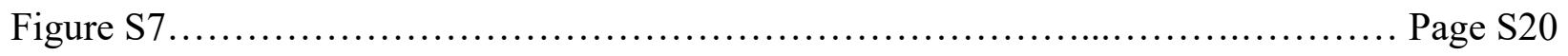

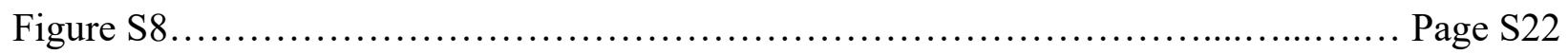

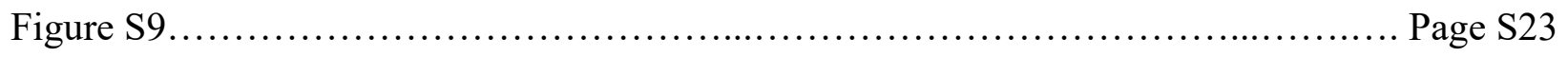

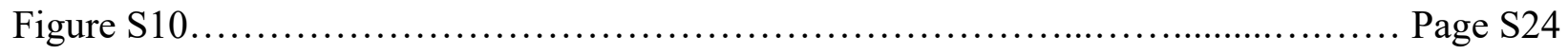

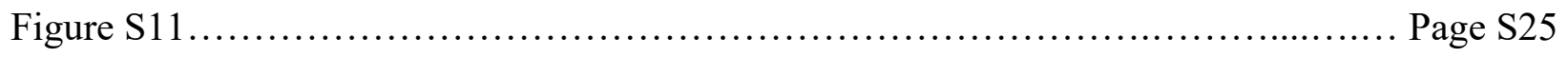

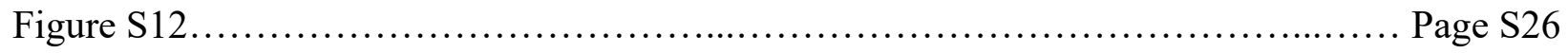

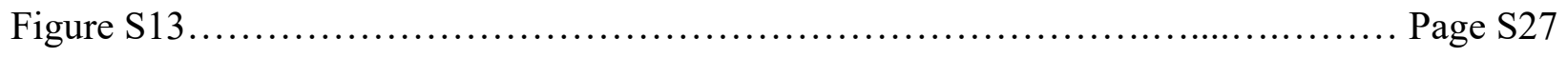

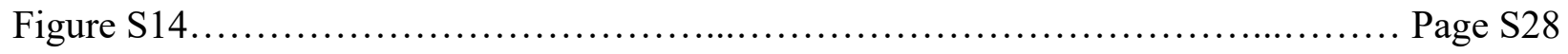

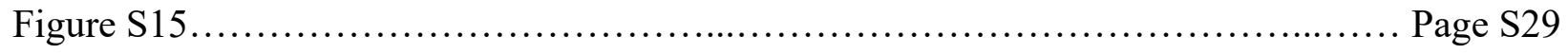

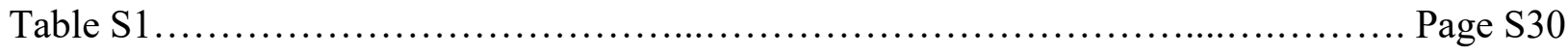

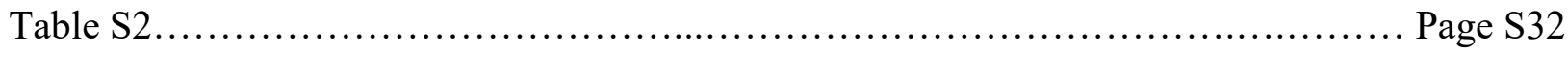

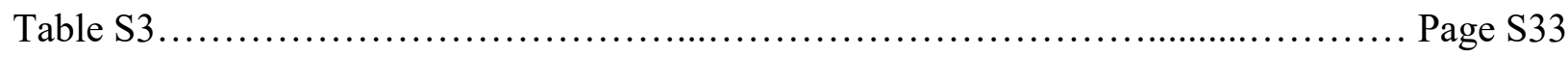

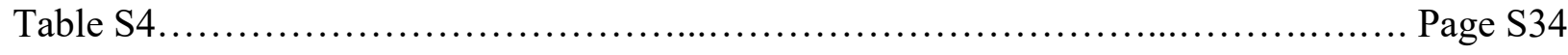

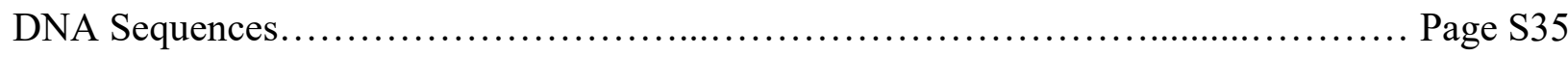

Protein Sequences..................................................... Page S37

Supporting References...................................................... Page S38 


\section{Materials and Methods}

General information. Chemicals were purchased from Thermo Fisher Scientific or SigmaAldrich unless stated otherwise. DNA sequencing was performed by the UC Berkeley DNA sequencing facility (Berkeley, CA). Amino acid analysis was performed by the UC Davis Molecular Structure Facility (Davis, CA). Mass spectrometry (MS) analysis of proteins and peptides was performed in the UC Berkeley QB3/Chemistry Mass Spectrometry Facility (Berkeley, CA). Synthetic DNAs were synthesized by Genscript (Piscataway, NJ). Primers for mutagenesis were purchased from Eurofins (Louisville, KY). The His-tagged TEV protease was purchased from UC Berkeley QB3 MacroLab (Berkeley, CA). Anaerobic experiments were conducted in the Plas-Labs Anaerobic chamber (Lansing, MI). $\mathrm{O}_{2}$ level in the anaerobic chamber was measured using a Teledyne Analytical Instruments Model 3110 Portable Oxygen Analyzer (City of Industry, CA). All the protein samples in EPR measurements were flash-frozen immediately after purification without any freeze-thaw cycle. The protein samples for native MS, reduction potential measurements and activity assays were frozen after purification, stored in liquid $\mathrm{N}_{2}$, and thawed immediately before use.

Bioinformatic analysis. The ligand environment analysis for either [2Fe-2S] or [4Fe-4S] cluster proteins was conducted using protein structures in the PDB released before September 2019. A requirement of $90 \%$ sequence identity was applied to narrow down the analyte and avoid the redundancy of repeating sequences in the database. The protein structures were screened individually to identify the iron-sulfur clusters that were directly coordinated by Cys in the CXC motif.

Plasmid generation. Genes of N-terminal Strep-tagged MexPqqE (protein ID: ACS39592.1) and N-terminal Strep-tagged MexFerredoxin (protein ID: ACS42518.1) were codon-optimized, synthesized and inserted into pET28b between NdeI and XhoI sites. The gene of C-terminal Histagged PqqAD fusion was designed, codon-optimized, synthesized and inserted into pET32a between NdeI and XhoI sites. All the PqqE variants were generated using the QuikChange ${ }^{\circledR}$ method, and primer sequences are listed in Table S3. The DNA sequences of the mutations were confirmed by Sanger DNA Sequencing using the T7 forward and reverse primers. 
SAM preparation. Commercially available SAM was used in the sample preparation for electrochemical experiments. SAM used in the enzymatic activity analysis was prepared freshly before the reaction using the method published elsewhere. ${ }^{1}$

PqqE expression and purification. The expression of the Strep-tagged PqqE was adapted from His-tagged PqqE with modification. ${ }^{1}$ The plasmid containing the gene of N-terminal Streptagged PqqE was co-transformed with the pPH151 plasmid in BL21(DE3) Gold competent cells. The transformed cells were introduced into LB media containing $50 \mathrm{ng} / \mathrm{mL}$ kanamycin and 50 $\mathrm{ng} / \mathrm{mL}$ chloramphenicol and shaken at $37^{\circ} \mathrm{C}$ for 20 hours. $20 \mathrm{~mL}$ of this culture was added into 2 L terrific broth media in a 4-L flask supplied with $50 \mathrm{ng} / \mathrm{mL}$ kanamycin, $50 \mathrm{ng} / \mathrm{mL}$ chloramphenicol, $200 \mu \mathrm{M}$ ammonium iron(III) citrate and $500 \mu \mathrm{M} \mathrm{MgSO}_{4}$. The culture was shaken at $31{ }^{\circ} \mathrm{C}$ and $180 \mathrm{rpm}$ until $\mathrm{OD}_{600}$ reached 0.5 , followed by lowering the shaker temperature to $18^{\circ} \mathrm{C}$ and shaking at $90 \mathrm{rpm}$ for 1 hour. The protein expression was initiated by the addition of $100 \mu \mathrm{M}$ isopropyl $\beta$-D-1-thiogalactopyranoside (IPTG) and $100 \mu \mathrm{M}$ L-cysteine. After 18 -hour expression at $18^{\circ} \mathrm{C}$ and $90 \mathrm{rpm}$, cells were harvested by centrifugation at 3500 rpm for 20 min at $4{ }^{\circ} \mathrm{C}$, and flash-frozen in liquid $\mathrm{N}_{2}$. The PqqE variants were expressed using the same method. All the protein expression started from fresh co-transformation into competent cells. Each $2 \mathrm{~L}$ of expression generally produces wet cell pellet of $\sim 10 \mathrm{~g}$ regardless of the type of protein. Strep-tagged PqqE was purified in the anaerobic chamber with $\mathrm{O}_{2}$ concentration lower than $0.4 \mathrm{ppm}$. The purification procedure was modified from the user manual of QIAGEN StrepTactin Superflow Plus. Briefly, each $10 \mathrm{~g}$ of cell pellet was lysed by stirring in $20 \mathrm{~mL}$ of $50 \mathrm{mM}$ sodium HEPES, $150 \mathrm{mM} \mathrm{KCl,} 500 \mu \mathrm{M}$ DTT, pH 7.9 with the addition of $2.5 \mathrm{~mL}$ of BugBuster® 10X Protein Extraction Reagent, $2.5 \mu \mathrm{L}$ of Benzonase ${ }^{\circledR}$ Nuclease and $25 \mathrm{mg}$ lysozyme from chicken egg white for 1 hour. The resulting lysate was then brought out of the anaerobic chamber in a sealed centrifuge bottle and centrifuged at 20,000 rpm for $30 \mathrm{~min}$ at $4{ }^{\circ} \mathrm{C}$. After bringing the lysate back into the anaerobic chamber, the supernatant was loaded onto a 10-mL Strep-Tactin Superflow Plus column equilibrated with $50 \mathrm{mM}$ sodium HEPES, $150 \mathrm{mM} \mathrm{KCl,} 500 \mu \mathrm{M}$ DTT, $\mathrm{pH}$ 7.9. The column then was washed by $20 \mathrm{~mL}$ of $50 \mathrm{mM}$ sodium HEPES, $150 \mathrm{mM} \mathrm{KCl,} 500$ $\mu \mathrm{M}$ DTT, pH 7.9. The protein was eluted by $50 \mathrm{mM}$ sodium HEPES, $150 \mathrm{mM} \mathrm{KCl,} 500 \mu \mathrm{M}$ DTT, $3 \mathrm{mM}$ desthiobiotin, $\mathrm{pH}$ 7.9. The protein solution was then concentrated to the designated concentration using an Amicon Ultra $30 \mathrm{~K}-0.5 \mathrm{~mL}$ spin filter. The PqqE variants were purified using the same method as described above. The resulting protein was used to prepare the EPR 
sample directly or store in liquid $\mathrm{N}_{2}$ for further use. For the anaerobic expression of PqqE, the procedure was the same as regular expression until the $\mathrm{OD}_{600}$ reaches 0.3 except in a sealed $4 \mathrm{~L}$ bottle. At $\mathrm{OD}_{600}=0.3$, the cell culture was taken out of the shaker and bubbled with $\mathrm{N}_{2}$ until the $\mathrm{OD}_{600}=0.5$ at the room temperature. The container was then transferred into the anaerobic chamber for induction and expression overnight with vigorously stirring. The wet weight of the cell pellet from the anaerobic expression is approximately half of the weight using the regular expression protocol. (Figure S8)

Protein concentration and amino acid analysis. Protein concentration was determined by Bradford reagent using BSA as standard. The PqqE sample for amino acid analysis was prepared using the procedure published elsewhere. ${ }^{2}$ Briefly, the protein solution was exchanged into 50 $\mathrm{mM}$ Tris, $100 \mathrm{mM} \mathrm{KCl}$, pH 7.9 using a PD-10 column. The resulting sample was aliquoted to $200 \mu \mathrm{L}$ in 4 tubes. One tube was used for Bradford assay and the other three tubes were sent out for amino acid analysis. The ratio of the concentrations calculated from the amino acid analysis and Bradford assay was used as the correction factor in all the concentration calculations of PqqE. The conversion factor was determined to be 0.85 for PqqE. Therefore, the concentration obtained from the Bradford assay was multiplied by the conversion factor.

Iron and sulfur content of PqqE. The iron and sulfur content of PqqE was determined using the method published elsewhere. ${ }^{1}$

Native MS sample preparation and measurements. The freshly purified protein was buffer exchanged into $50 \mathrm{mM}$ ammonium carbonate, $\mathrm{pH}$ 7.9, using the PD-10 column in the anaerobic chamber. The protein solution was sealed in a GC vial and brought out of the anaerobic chamber right before the MS analysis. Native mass spectra were acquired using a Synapt G2-Si mass spectrometer equipped with a nanoelectrospray ionization source (Waters, Milford, MA), as described elsewhere. ${ }^{3}$ Data acquisition and processing were performed using MassLynx software (version 4.1, Waters).

Determination of reduction potentials for $\mathbf{P q q E}$ and variants. Electrochemical experiments were performed with a PGSTAT 12 potentiostat (EcoChemie) under anaerobic conditions in an MBraun Labmaster glovebox under a nitrogen atmosphere. A three-electrode configuration was used where the reference electrode was a standard calomel electrode and the counter electrode was a platinum wire and the temperature of the cell was controlled by a water jacket. All potentials are 
reported relative to a standard hydrogen electrode (SHE). Baseline scans were measured using a pyrolytic graphite edge (PGE) electrode that had been pretreated by mechanical polishing with sandpaper followed by incubating overnight with $20 \mu \mathrm{L}$ of a solution of $3 \mathrm{mg}$ of multi-walled carbon nanotubes (MWCNT) (Sigma, $10 \mathrm{~nm} \pm 1 \mathrm{~nm} \times 4.5 \mathrm{~nm} \pm 0.5 \mathrm{~nm} \times 3-\sim 6 \mu \mathrm{m}$ ) dissolved in $1 \mathrm{~mL}$ of dimethylformamide (DMF) using sonication for 15 minutes (McDowall et al. 2014). Electrodes were placed in the electrochemical cell containing a mixed buffer solution $(10 \mathrm{mM}$ MES, CHES, HEPES, CAPS, and TAPS, $200 \mathrm{mM} \mathrm{NaCl}$, and $\mathrm{pH}$ 7.5) that was maintained at $4{ }^{\circ} \mathrm{C}$. A 4-6 $\mu \mathrm{L}$ aliquot of PqqE or variant $(\sim 250 \mu \mathrm{M})$ was deposited directly on the PGE electrode modified with MWCNT and allowed to sit for $\sim 4$ minutes at room temperature after which the electrode was rinsed and returned to the buffer solution in the electrochemical cell. All cyclic voltammograms were measured over a potential range of $-158 \mathrm{mV}$ to $-958 \mathrm{mV}$ vs. SHE or $14 \mathrm{mV}$ to $-586 \mathrm{mV}$ at scan rates ranging from $50 \mathrm{mV} / \mathrm{s}$ to $200 \mathrm{mV} / \mathrm{s}$. Square wave voltammograms were measured over the same potential ranges with a frequency of $15 \mathrm{~Hz}$ or $10 \mathrm{~Hz}$ and an amplitude of $50 \mathrm{mV}$. Non-turnover electrochemical signals were analyzed by correcting the non-Faradaic component of the current from the raw data using the QSoaS package ${ }^{4}$. To study the effect of SAM, $R S$ only was incubated with SAM (7 mM) for 30 seconds before being deposited directly on the PGE electrode modified with MWCNT. This was characterized via square wave voltammetry after one minute of exposure to SAM at a frequency of $15 \mathrm{~Hz}$ and an amplitude of $20 \mathrm{mV}$, at $4{ }^{\circ} \mathrm{C}$ and $\mathrm{pH} 7.5$.

EPR sample preparation and measurements. All EPR samples were prepared in the anaerobic chamber from freshly purified protein without freeze and thaw. For dithionite (DTH) reduced sample, 10 equivalents of DTH was added into the PqqE sample and transferred to X-band or Kband EPR quartz for $15 \mathrm{~min}$ incubation in the anaerobic chamber before being quickly flashfrozen in liquid $\mathrm{N}_{2}$ outside of the anaerobic chamber. Ti(III) citrate was prepared freshly before use. The method of $\mathrm{Ti}(\mathrm{III})$ citrate was modified from the previously published method. ${ }^{5}$ Briefly, $5 \mu \mathrm{L}$ of $15 \%$ Ti(III) chloride solution was added into $50 \mu \mathrm{L}$ of $200 \mathrm{mM}$ sodium citrate and the resulting solution was neutralized by the addition of $10 \mu \mathrm{L}$ saturated sodium carbonate. $20 \mu \mathrm{L}$ of this Ti(III) citrate solution was then used to reduce $200 \mu \mathrm{L}$ of $200 \mu \mathrm{M}$ PqqE and its variants. The EPR sample was flash-frozen in liquid $\mathrm{N}_{2}$ after $1 \mathrm{~h}$ incubation in the anaerobic chamber. 
PqqE activity assays. The PqqE activity was determined based on the production of 5'deoxyadenosine and crosslinked PqqA. The reaction was performed in the anaerobic chamber in $100-\mu \mathrm{L}$ scale. The catalysis was initiated by addition of $2 \mathrm{mM}$ SAM in a pre-incubated reaction mixture containing $150 \mu \mathrm{M}$ PqqE or variants, $900 \mu \mathrm{M}$ NADPH, $24 \mu \mathrm{M}$ ferredoxin-NADP ${ }^{+}$

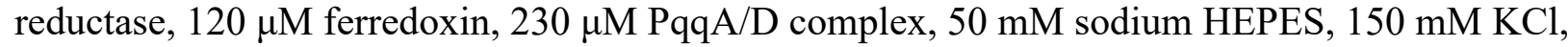
$250 \mu \mathrm{M}$ DTT, $200 \mu \mathrm{M}$ TCEP, $1.5 \mathrm{mM}$ desthiobiotin, $\mathrm{pH}$ 7.9. The reaction was quenched by the addition of $1 \mu \mathrm{L}$ formic acid after 16-hour incubation with stiring. The production of 5'deoxyadenosine was quantified using commercially available 5'-deoxyadenosine as a standard. The same reaction mixture was diluted 5-fold into deionized water and analyzed for crosslinked PqqA using an LTQ-Orbitrap-XL mass spectrometer as described elsewhere. ${ }^{6}$ The concentration of PqqA crosslink was analyzed using the residual PqqA post-reaction as the reference assuming that PqqA and the crosslinked PqqA share a similar property in the concentration/MS intensity conversion. (Figure S9)

Iron-sulfur content in PqqE and variants. The iron and sulfur content of the as-purified PqqE is $10 \pm 1$ atoms per protein and $11 \pm 1$ atoms per protein as determined by the standard ferrozine assay and sulfur quantification methods, respectively, which are consistent with the previously published data using His-tagged protein. ${ }^{1}$ Chemical reconstitution post purification increased the iron and sulfur content to $12 \pm 1$ and $13 \pm 1$ atoms, respectively. The iron/sulfur contents of PqqE variants are listed in Table S4.

Ferredoxin expression and purification. MEXAM1_RS23225 and MEXAM1_RS20705 were annotated as [2Fe-2S]-binding ferredoxins (WP_003604694.1 and WP_003597514.1) in the genome of Methylorubrum extorquens. The codon-optimized gene MEXAM1_RS23225 and MEXAM1_RS20705 with a strep-tag fused at the N-terminus of the proteins in the constructs were synthesized by GenScript and inserted into the NcoI and XhoI of the pET28b. The plasmid containing each insertion was transformed into BL21(DE3) Gold competent cells and grown overnight in LB media supplied with $50 \mathrm{ng} / \mathrm{mL}$ kanamycin at $37^{\circ} \mathrm{C}$. The overnight cell culture was then diluted 100x in $2 \mathrm{~L}$ TB media containing $200 \mu \mathrm{M}$ ammonium iron(III) citrate , $500 \mu \mathrm{M}$ $\mathrm{MgSO}_{4}$ and $50 \mathrm{ng} / \mathrm{mL}$ kanamycin, and culture was incubated in a shaker at $37^{\circ} \mathrm{C}$ and $220 \mathrm{rpm}$ until $\mathrm{OD}_{600}$ reached 0.6 . The protein expression was initiated with $1 \mathrm{mM} \mathrm{IPTG}$ at $30{ }^{\circ} \mathrm{C}$, supplied with $100 \mu \mathrm{M}$ L-cysteine and shaken at $220 \mathrm{rpm}$ overnight. The protein purification was 
conducted in the glovebox using the same protocol as strep-tagged PqqE. The expression of gene MEXAM1_RS20705 yielded protein with no iron-sulfur cluster binding. The expression of gene MEXAM1_RS23225 produces a pink protein solution that exhibited a UV-vis absorbance feature of a typical [2Fe-2S] cluster. (Figure S10) We, therefore, used protein WP_003604694.1 as the ferredoxin in the biological reduction system.

Ferredoxin NADP ${ }^{+}$-reductase expression and purification. In the genome of Methylorubrum extorquens, MEXAM1_RS11025 was annotated as ferredoxin-NADP ${ }^{+}$reductase (WP 082289529.1). The codon-optimized MEXAM1_RS11025 with an N-terminal His $x_{x}$-tag was synthesized by GenScript and inserted between NdeI and XhoI sites in pET28b. The plasmid containing ferredoxin-NADP ${ }^{+}$reductase gene insertion was transformed into BL21(DE3) Gold competent cells and grown overnight in LB media supplied with $50 \mathrm{ng} / \mathrm{mL}$ kanamycin at $37^{\circ} \mathrm{C}$. The overnight cell culture was then diluted 100x in 2 L LB media containing $50 \mathrm{ng} / \mathrm{mL}$ kanamycin, and culture was incubated in a shaker at $37^{\circ} \mathrm{C}$ and $220 \mathrm{rpm}$ until $\mathrm{OD}_{600}$ reached 0.6. The protein expression was initiated with the addition of $1 \mathrm{mM}$ IPTG and supplied with $100 \mu \mathrm{M}$ riboflavin at $31^{\circ} \mathrm{C}$ and shaken at $220 \mathrm{rpm}$ overnight. The protein was harvested by centrifugation at $3500 \mathrm{rpm}$ for $20 \mathrm{~min}$. His-tagged ferredoxin-NADP ${ }^{+}$reductase was expressed using the method published elsewhere. ${ }^{1}$

Characterization of the ferredoxin and ferredoxin-NADP ${ }^{+}$reductase. Using standard iron and sulfur content assays, ferredoxin was purified containing 2.0 and 2.2 iron and sulfur atoms per protein molecule, respectively. The $[2 \mathrm{Fe}-2 \mathrm{~S}]$ cluster in the ferredoxin was also confirmed by the UV-vis spectrum. (Figure S10) Ferredoxin-NADP ${ }^{+}$reductase was purified containing FAD with the signature absorbance at $450 \mathrm{~nm}$.

Design of PqqAD fusion construct. In the past, PqqA was chemically synthesized using standard Fmoc solid-phase peptide synthesis service provided by CPC Scientific. The commercially available PqqA can be purified only to $80 \%$ purity due to the technical difficulties originating from the nature of the peptide sequence. Heteroexpression of PqqA directly in E. coli expression system was not able to produce a high quantity of peptide, presumably due to the presence of proteases in E. coli that cleave the peptide during expression. We, therefore, sought a method to co-express PqqA with highly soluble PqqD, which can facilitate the overexpression of PqqA in E. coli. We initially designed a pETDuet expression system, in which the PqqD 
sequence was inserted at MCS1 and PqqA sequence was inserted at MCS2. However, MS analysis of the purified protein solution failed to detect a significant amount of PqqA in the sample. We then designed a PqqAD fusion construct, in which PqqA was fused at the Nterminus of PqqD connected through a TEV protease cleavage site, and a TEV cleavable His 6 $^{-}$ tag was fused at the C-terminus of PqqD for the benefit of purification. The codon-optimized

gene was synthesized by Genscript and inserted into the pET32b vector between NdeI and XhoI restriction sites. The plasmid containing PqqAD fusion was transformed into BL21(DE3) Gold competent cells and grown overnight on LB media supplied with $100 \mathrm{ng} / \mathrm{mL}$ ampicillin at $37^{\circ} \mathrm{C}$. The overnight cell culture was then diluted 100x in $1.5 \mathrm{~L} \mathrm{LB}$ media containing $100 \mathrm{ng} / \mathrm{mL}$, and culture was incubated in a shaker at $37^{\circ} \mathrm{C}$ and $220 \mathrm{rpm}$ until $\mathrm{OD}_{600}$ reached 0.6. The protein expression was initiated with $1 \mathrm{mM} \mathrm{IPTG}$ at $30{ }^{\circ} \mathrm{C}$ and shaken at 220 rpm overnight. The protein purification was carried out using the Ni-NTA column as demonstrated previously. Using this method, we were able to produce up to $100 \mathrm{mg} / \mathrm{mL}$ of PqqAD fusion protein from 1.5 L cell culture. The protein molecular weight (calculated 16509.64 Da) was confirmed by MS. (Figure S11)

PqqA/D complex preparation. The as-purified PqqAD fusion protein was treated with Histagged TEV protease (QB3-UC Berkeley MacroLab) at a 1:6 mass ratio and incubated at $22{ }^{\circ} \mathrm{C}$ for 3 hours before being moved to a rocker and further incubated at $4{ }^{\circ} \mathrm{C}$ for 16 hours. The cleavage reaction mixture was then passed through the Ni-NTA column to remove the His-tag, His-tagged TEV protease, and the flow-through was collected. The column was washed with 1 column volume of $50 \mathrm{mM}$ sodium HEPES, $150 \mathrm{mM} \mathrm{KCl,} 1 \mathrm{mM}$ TCEP, $\mathrm{pH}$ 7.9, and combined with flow-through. The resulting solution was concentrated using Amicon Ultra $3 \mathrm{~K}-0.5 \mathrm{~mL}$ and flash-frozen in liquid $\mathrm{N}_{2}$. The cleavage was confirmed by SDS-PAGE and the production of PqqA was confirmed by MS. (Figure S12)

\section{Supplementary Note}

Native MS data analysis and the proposed iron-sulfur cluster configuration. LC-ESI-MS analysis of holo-PqqE identified an apo-form of PqqE with molecular weight $42986 \pm 1 \mathrm{Da}$ (theoretical $42987 \mathrm{Da}$ ). Due to the presence of iron-sulfur clusters during aerobic intact protein LC-MS analysis, sulfide additions to cysteine due to the oxidative damage were observed as 
well. (Figure S14) These additional species did not appear in the spectra of the native MS samples. Under the native condition, 10 cysteines used as ligands of iron at three iron-sulfur cluster centers are deprotonated, which gives the mass of 42977 Da. Mass of ligands was calculated by subtracting 42977 Da from the deconvoluted holo-protein mass, which represents the potential iron-sulfur clusters and other possible ion adducts carried over from the purification process. The proposed iron/sulfur contents were calculated based on the best-fit iron and sulfur counts taking into consideration the chemical nature of the binding sites. Briefly, we first identified that Species F corresponds to the holo-PqqE with two [4Fe-4S] and one [2Fe-2S] clusters, which has been confirmed via different methods discussed in the main text. The lower molecular weight species are potential breakdown products from Species $\mathrm{F}$ formed before or during the native MS measurement. On the basis of the mass difference between each species, loss of sulfur/iron atoms was fitted in the breakdown products. The possible iron-sulfur cluster configurations were assigned based on the previously assigned configuration in PqqE as well as other iron-sulfur containing proteins. For example, the adduction of sodium ions without disrupting the major charge states of the sample has been reported in previous studies using native MS. ${ }^{8-10}$ PqqE purification buffer was made from sodium HEPES, therefore, Species H was assigned as the holo-PqqE with three [4Fe-4S] clusters and an extra sodium ion. In Species I, the extra sulfur is predicted to be a degradation product from other protein molecules in the solution and is possibly added onto the open coordination site at the RS [4Fe-4S] cluster. Such geometry has been shown in the crystal structure of Pyrococcus horikoshii TtuA. ${ }^{11}$ Other combinations of the iron-sulfur clusters are also possible.

PqqE variants. Ligands of the iron-sulfur cluster at each site include C28/C32/C35 (RS), C248C268/C323/C325 (AuxI) and C310/C313/D319/C341 (AuxII). The cluster knockouts replace at least two cysteines with alanines. For the AuxI knockouts $(R S / A u x I I)$, we generated two different combinations of variants C248A/C268A and C323A/C325A. The iron and sulfur contents of the PqqE variant with alanine replacement at C323/C325 were $5 \pm 1$ and $4 \pm 1$ atoms per molecule, respectively. Those values are lower than the iron and sulfur contents of the C248A/C268A variants (Table S4), which implies that more iron-sulfur cluster is damaged in this variant. Residue C323 and C325 are located on the loop between AuxI and AuxII and we believe that the replacement at C323 and C325 disrupts the cluster loading at AuxII site as well. 
All the measurements of the AuxI knockout reported in this study used the C248A/C268A variant. For the $R S$ only variant, we generated the variant $\mathrm{C} 310 \mathrm{~A} / \mathrm{C} 313 \mathrm{~A} / \mathrm{C} 323 \mathrm{~A} / \mathrm{C} 325 \mathrm{~A}$, which successfully knocked out the two auxiliary clusters based on its iron/sulfur content as well as minimized the perturbation on the protein near the RS site. ${ }^{7}$

EPR analysis. We note that almost all of the EPR and electrochemistry measurements reported herein have been carried out in the absence of PqqD and peptide substrate. It is possible that the formation of a ternary complex, involving $\mathrm{PqqE} / \mathrm{PqqD} / \mathrm{PqqA}$, could alter the apparent redox potentials, and differentially at each iron-sulfur site. However, the trends that we see among all the constructs in Table 3, while noteworthy, are not exceedingly large in any instance with the possible exception of the more positive potential measured with AuxI only. There are currently no compelling data regarding the role of AuxI in binding either PqqD to PqqE or the complex of the peptide chaperone with PqqA and this is an important next direction.

\section{Low reduction potential feature in electrochemical measurements. Previously, we} established that it was possible to incorporate either [2Fe-2S] or [4Fe-4S] at the AuxI site, and the $[4 \mathrm{Fe}-4 \mathrm{~S}]$ cluster could only be reduced by Ti(III) citrate or Eu(II)-DTPA. We, therefore, expanded the scanning window of the WT PqqE to go as low as $-1.1 \mathrm{~V}$ in cyclic and square wave voltammetry experiments. A feature is clearly observed at $-800 \mathrm{mV}$ vs. SHE in WT PqqE and a wide range of variants (including $R S / C 268 H / A u x I I)$. But it was not clearly associated with a single cluster binding site (Figure S7). Low reduction potential iron-sulfur clusters have been reported in the past for $[3 \mathrm{Fe}-4 \mathrm{~S}]^{0 / 2}$ in $D$. africanus ferredoxin ${ }^{12}$ and the $[4 \mathrm{Fe}-4 \mathrm{~S}]^{+2 /+1}$ at the auxiliary site of twitch domain RS enzyme BtrN. ${ }^{13}$ However, the low potential feature in PqqE is unexpectedly unique from either case: First, the shape of the peak for the two-electron transfer in $[3 \mathrm{Fe}-4 \mathrm{~S}]^{0 / 2}$ is much sharper than observed in PqqE, which makes it less likely to be a major contributor. Second, unlike BtrN where the reduction potential feature around $-500 \mathrm{mV}$ completely disappeared in the BtrN RS knockout, both the very low and more positive potentials remain observable in the $R S$ only variant of PqqE. Thus, the low potential feature cannot be primarily coming from the $[4 \mathrm{Fe}-4 \mathrm{~S}]^{+2 /+1}$ of AuxI site as it is clearly present even when this site is empty. (Figure S7 and Table S2) Also, from the native MS analysis, a protein with AuxI [4Fe$4 \mathrm{~S}$ ] cluster is present at a significantly lower abundance than the protein containing a [2Fe-2S] at 
the AuxI site. It is possible that only a small fraction of low potential feature may be generated from a $[4 \mathrm{Fe}-4 \mathrm{~S}]^{+2 /+1}$ signal that overlaps with a low potential species $[3 \mathrm{Fe}-4 \mathrm{~S}]^{0 /-2}$ (as shown in Figure S13 there are both [3Fe-4S] and [4Fe-4S] cluster present in the $R S$ only variant). The true identity and origin of this very negative potential in RS PqqE is still under investigation and may be due to a mixture of several redox-active species.

We note that the low potential feature does not clearly associate with a single cluster based on the cluster knockout study. If the newly proposed [4Fe-4S] cluster exhibited low reduction potential, WT, RS/AuxI/D319H, RS/AuxI/D319C, RS/AuxI, AuxI/AuxII, and AuxI only are predicted to show the low potential feature, and $R S$ only, $R S / D 319 C$ and $R S / A u x I I$ are predicted to show no low potential feature. However, we indeed observe $R S$ only exhibited low potential feature, yet AuxI only, RS/AuxI/D319C, and AuxI/AuxII shows no apparent low potential feature. As discussed in the main text, the $R S$ only suggested that it might arise from an overlap of multiple species. Experimentally, we have confirmed by EPR that $R S$ only does not contain a $[4 \mathrm{Fe}-4 \mathrm{~S}]$ cluster even though the ligands at the AuxI site were intact. This could explain why no low potential feature was observed at this variant. However, we have observed the signal raised from putative [4Fe-4S] cluster at the AuxI/AuxII in EPR, yet it was not detected electrochemically. We note that the reversibility of the cyclic voltammetry for $R S / A u x I / D 319 C$ and $A u x I / A u x I I$ was weaker than any other variant. It is also possible that the absence of the signal was due to the instability of the protein itself on the electrode, thus limiting our detection capability. We cannot yet assign the low potential feature to individual species due to the complexity of this multi-cluster system. The latter is clearly different from what has been observed in BtrN and other reported iron-sulfur cluster containing proteins.

Native MS of $R S / C 268 H / A u x I I$. Using the same method as described previously for WT protein analysis, we performed native MS analysis for RS/C268H/AuxII. (Figure S14) However, the resulting mass spectrum lacks well-defined individual species but, instead, shows a broad feature containing various species. This suggests complex degradation products forming during the process of measurement. We also observed the degradation process during the time course of the measurement, in which the signal envelope shifted toward lower molecular mass over the 30-s measurement period. This also indicates a much less stable protein environment for the occupation of iron-sulfur clusters compared to WT PqqE. The EPR measurements show that this 
variant only contains a [4Fe-4S] cluster at the AuxI site (Figure 8), and this cluster can only be reduced by low potential reductant $\mathrm{Ti}(\mathrm{III})$ or $\mathrm{Eu}(\mathrm{II})$. Therefore it is reasonable that this cluster is more susceptible to oxidative damage and is much less stable than other clusters in PqqE. 

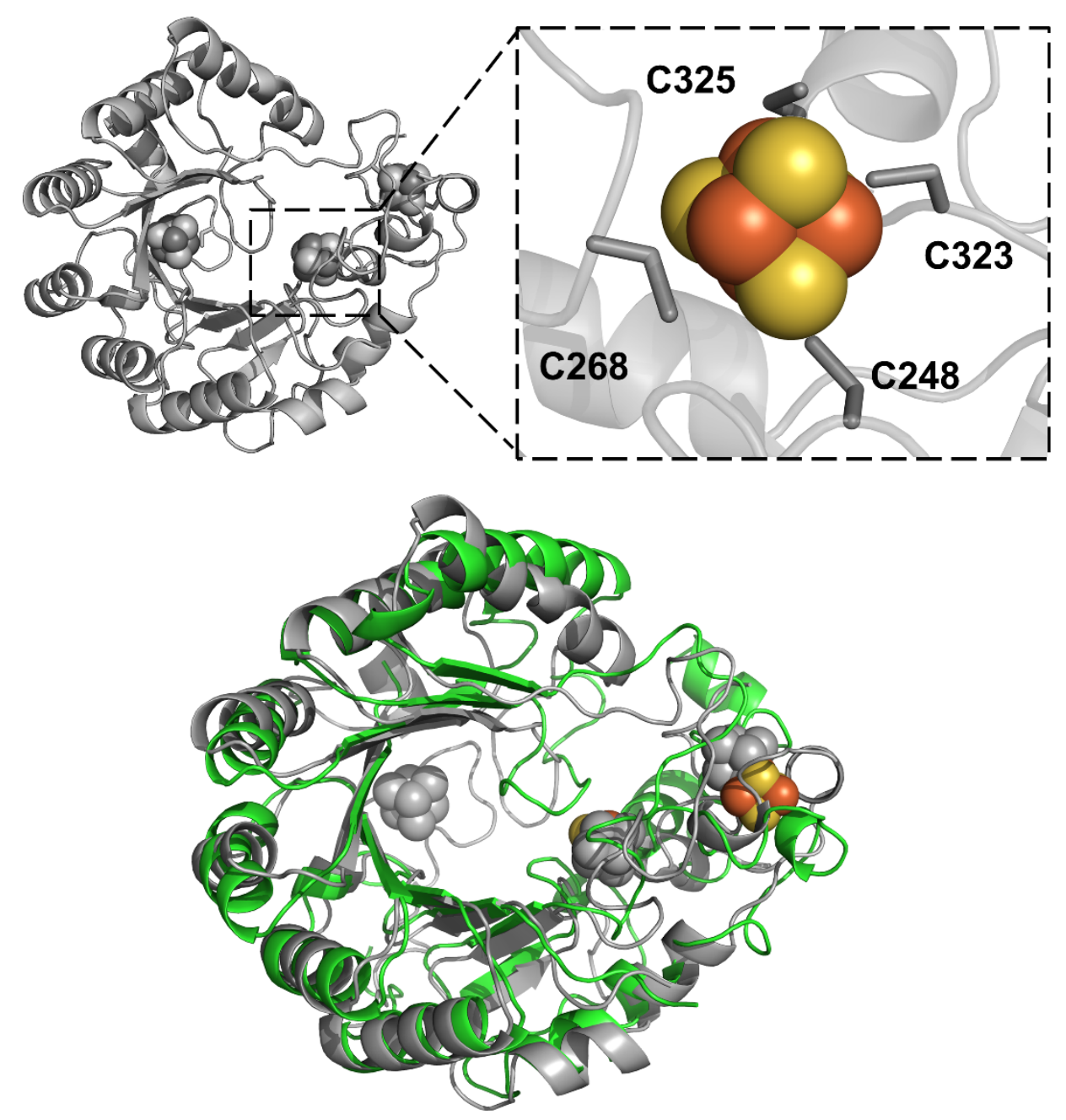

Figure S1 Model of the predicted ligand environment of the previously identified [4Fe-4S] cluster species via EPR analysis. A four-cysteine liganded [4Fe-4S] cluster at the AuxI site of PqqE was assigned based on the EPR active species with $g=2.104$ when PqqE is reduced by Ti(III) citrate. ${ }^{5,7}$ The top-left structure model of PqqE presented here is generated by SWISSMODEL using SuiB as a template (PDB: 5V1Q) and the protein backbone is superimposed on the iron-sulfur clusters in 5V1Q. The zoom-in shows the possible ligand environment of this [4Fe-4S] center at the AuxI site in the PqqE structural model. The bottom structure shows the superimposed PqqE crystal structure (green) with [2Fe-2S] cluster at AuxI (yellow for sulfur and orange for iron) and the predicted PqqE model with [4Fe-4S] cluster at AuxI (gray). A structural difference is expected at the SPASM domain when AuxI is loaded with different iron-sulfur clusters. 


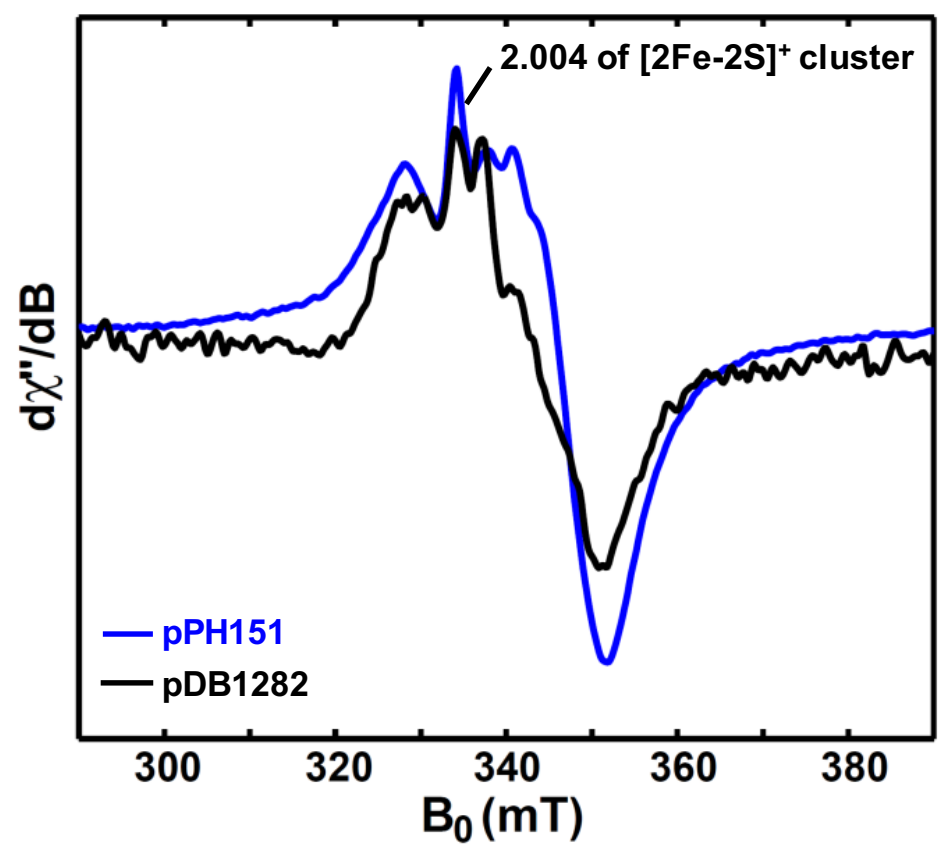

Figure S2. EPR measurement of WT PqqE using various iron-sulfur cluster assembly systems during expression. X-band $\mathrm{CW}$ EPR spectra $(9.37 \mathrm{GHz}, 10 \mathrm{~K})$ of dithionitereduced His-tagged WT PqqE when co-expressed with pDB1282 (black trace) or pPH151 (blue trace). 


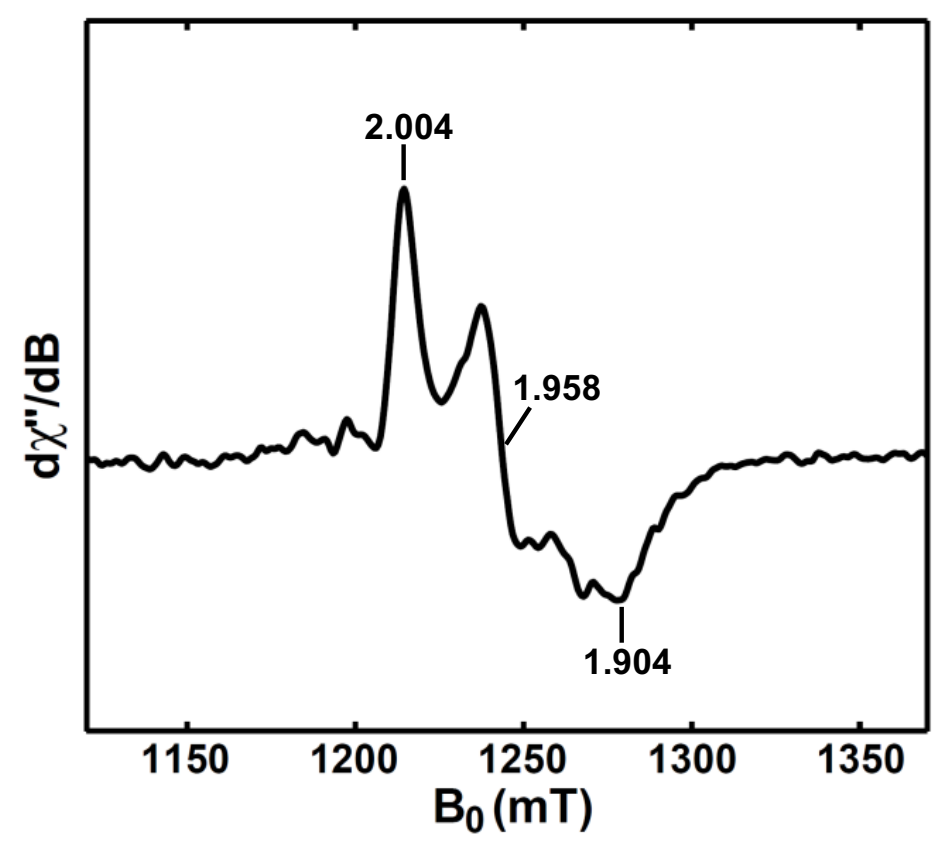

Figure S3. EPR measurement of WT PqqE after removal of iron-sulfur cluster and reconstitution with synthetic $[\mathbf{4 F e}-4 \mathrm{~S}]$ cluster. Q-band $(34.0 \mathrm{GHz}, 10 \mathrm{~K})$ pseudo-modulated electron spin-echo detected field-swept EPR spectrum of dithionite-reduced apo WT PqqE reconstituted with synthetic [4Fe-4S]. 
Methylobacterium_extorquens

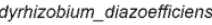
Hyphomicrobium_sp.

Acetobacter_pomoru

Sphingomonas_sp.

Pseudogulbenkiania_sp.

Azospirillum_sp.

Sinorhizobium_sp.

Paracoccus_yeei

Pseudonocardia_aln

Streptomyces_sp.

Mycobacterium_smegmatis

Nostoc_flagelliforme

Paenibacillus rhizosphaerae

Pseudomonas mendocina

Azotobacter beijerincki

Cystobacter_fuscus

Klebsiella pneumonia

Enterobacter cloacae

Cronobacter sakazakil

Marinobacter halophilus

Acinetobacter colcoacetious

Psychrobacter_sp.

Halomonas_endophytica

Methylomonas_sp.

Chromatiaceae_bacterium

Porticoccaceae_bacterium

Solimonas_aquatica

Thauera_sp

Burkholderia_cepacia

Paraburkholderia_xenovorans

Caballeronia_fortuita

Massilia_psychrophila

Variovorax_boronicumulans

Methylophaga_nitratireducenticrescens

Methylotenera_sp.

Arcobacter sp.

Methylacidiphilum_infernorum

Methylobacterium_extorquens

Bradyrhizobium diazoefficiens

Hyphomicrobium_sp.

Acetobacter_pomorum

Sphingomonas_sp.

Pseudogulbenkiania_sp.

Azospirillum_sp.

Sinorhizobium_sp.

Paracoccus_yeei

Pseudonocardia_aln

Streptomyces_sp.

Mycobacterium_smegmatis

Nostoc_flagelliforme

Amycolatopsis sp.

Paenibacillus rhizosphaerae

Pseudomonas_mendocina

Azotobacter_beijerinc

Cystobacter_fuscus

Klebsiella a pneumoniae

Pluralibacter_gergoviae

Cronobacter sakazaki

Marinobacter halophilu

Acinetobecter caphilus

Psychrobacter_sp.

Halomonas_endophytica

Methylomonas sp.

Chromatiaceae bacterium

Porticoccaceae bacterium

Solimonas_aquatica

Thauera sp.

Burkholderia cepacia

Paraburkholderia xenovorans

Caballeronia_fortuita

Melhylophaga_nitratireducenticrescens

Methylotenera_sp.

Methylacidiphilum_infernorum
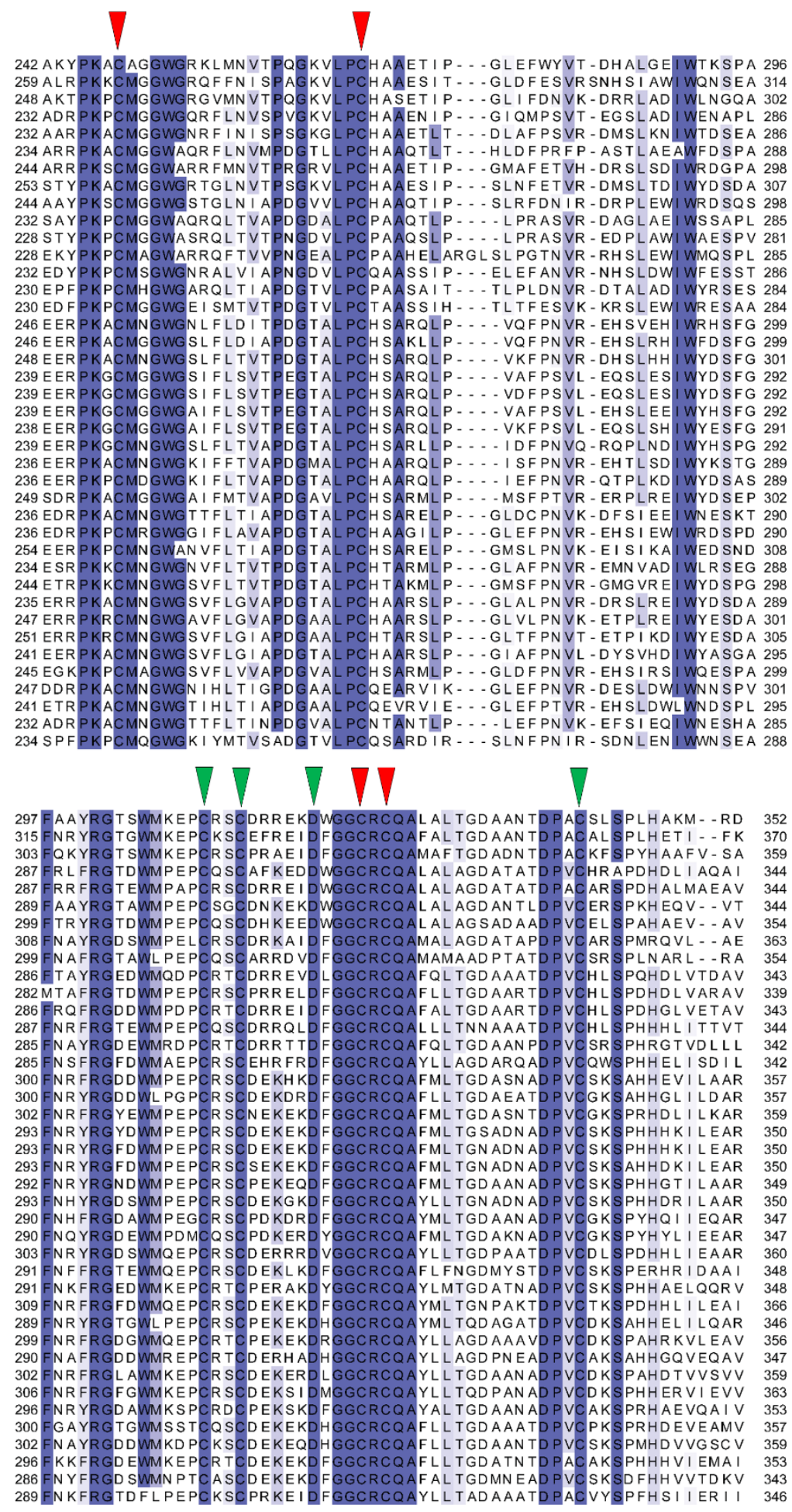

$\nabla$ Auxl $\quad$ Auxll

Figure S4. Sequence alignment of the PqqE in various organisms. The AuxI ligands are denoted by red triangles, and the AuxII ligands are denoted by green triangles. The residues highlighted in blue have $>50 \%$ conservation and the shades of blue represent $\%$ conservation. 


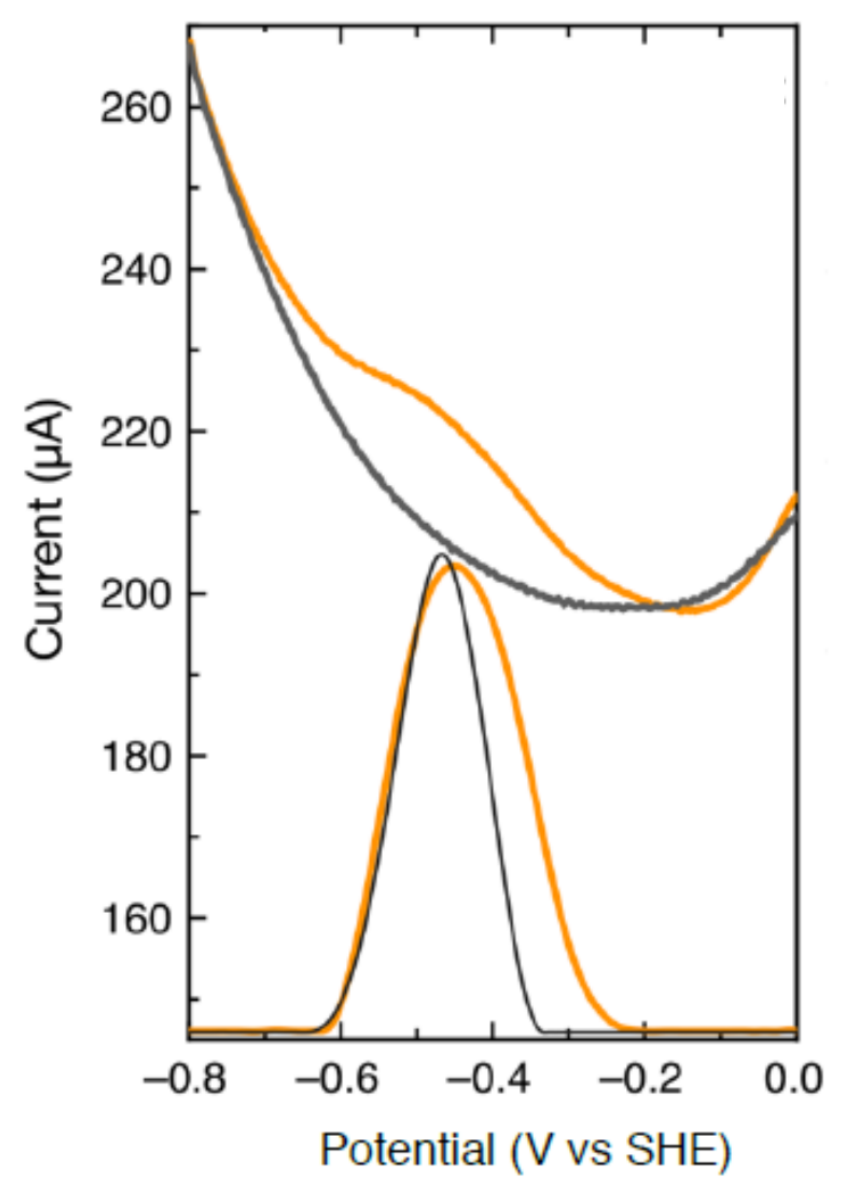

Figure S5. Reduction potential measurement of $\boldsymbol{R S}$ only in the presence of SAM. The $R S$ only + SAM sample is shown in yellow and the baseline is shown in black. Square wave voltammograms of PqqE RS only in the presence of SAM on an PGE electrode with MWCNT measured with a frequency of $15 \mathrm{~Hz}$ and an amplitude of $20 \mathrm{mV}$ at $4{ }^{\circ} \mathrm{C}, \mathrm{pH} 7.5$ 
A)

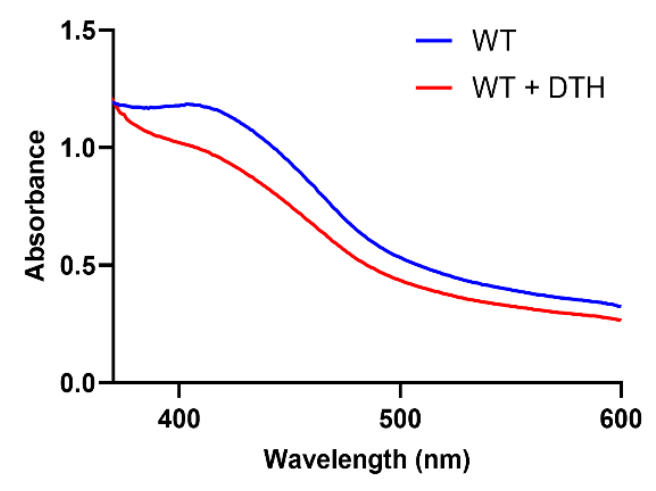

C)

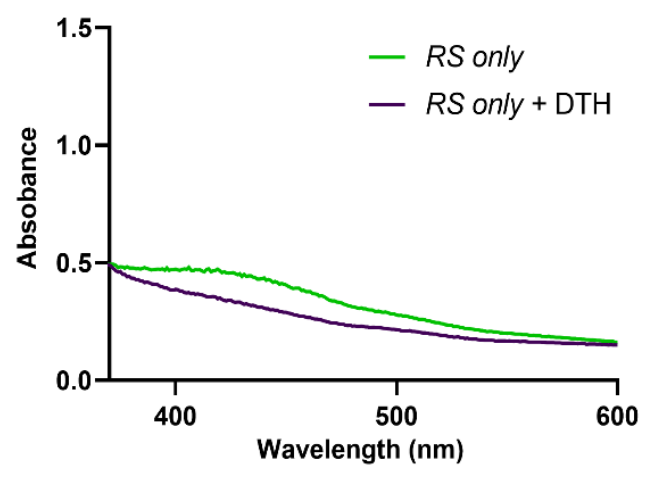

B)

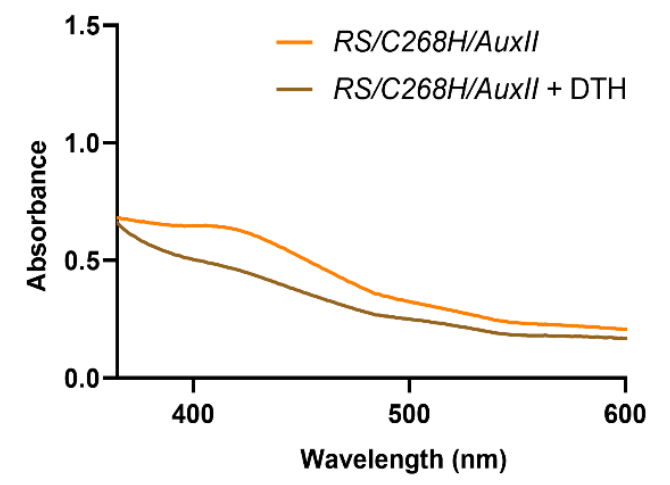

D)

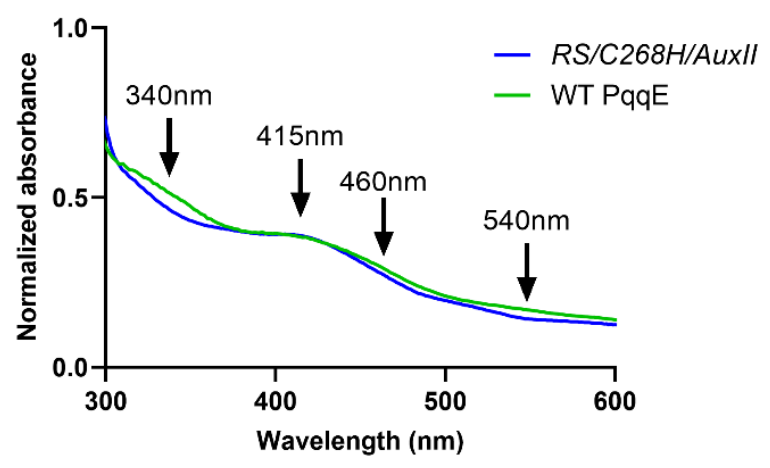

Figure S6. UV-vis spectra of WT PqqE and its variants in the absence/presence of dithionite. UV-vis spectra of A) WT PqqE B) $R S / C 268 H / A u x I I$, C) $R S$ only, and D) $R S / C 268 H / A u x I I$ scaled to the same intensity as $W T$ at $415 \mathrm{~nm}$. In the as-purified WT and variants of PqqE, a signature [4Fe-4S] cluster feature appeared at $415 \mathrm{~nm}$. This peak disappeared when 10 equivalents of sodium dithionite was added. When the signal of WT was normalized to that of $R S / C 268 H / A u x I I$ at $415 \mathrm{~nm}$, a significant difference between $R S / C 268 H / A u x I I$ and WT appeared at $340 \mathrm{~nm}$. This feature represented the presence of [2Fe-2S] species in WT, yet it was not detected for $R S / C 268 H / A$ uxII. 

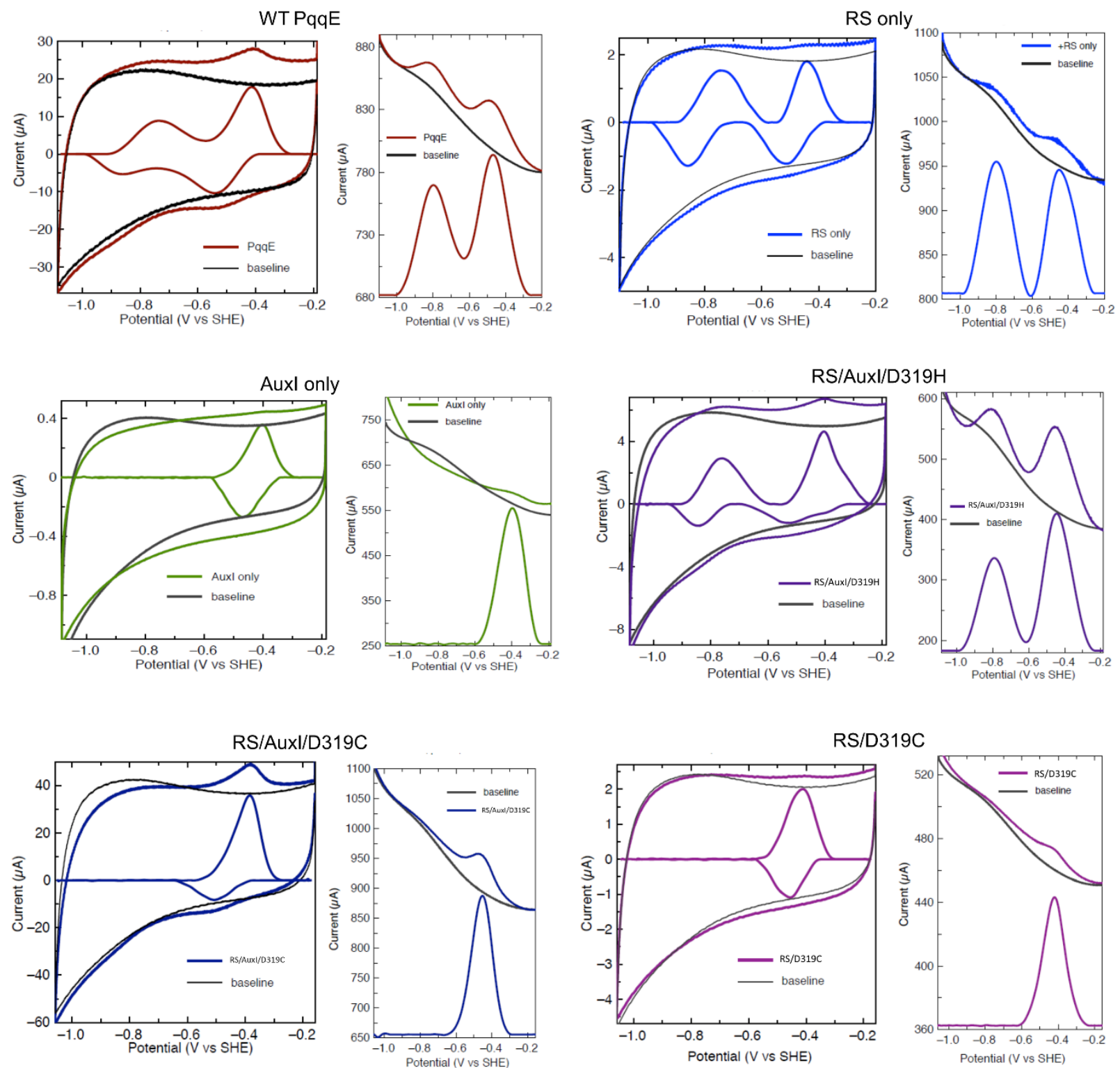

Figure S7. The electrochemical measurement of WT PqqE and its variants reveal the low potential species. The reduction potential measurements of WT PqqE and its variants. The measurement windows were expanded to $-1.5 \mathrm{~V}$. The colored lines are the measurements for each protein and the black lines are the baseline measurements. For each protein, the cyclic voltammetry measurement is shown on the left and the square wave voltammetry measurement is on the right. 

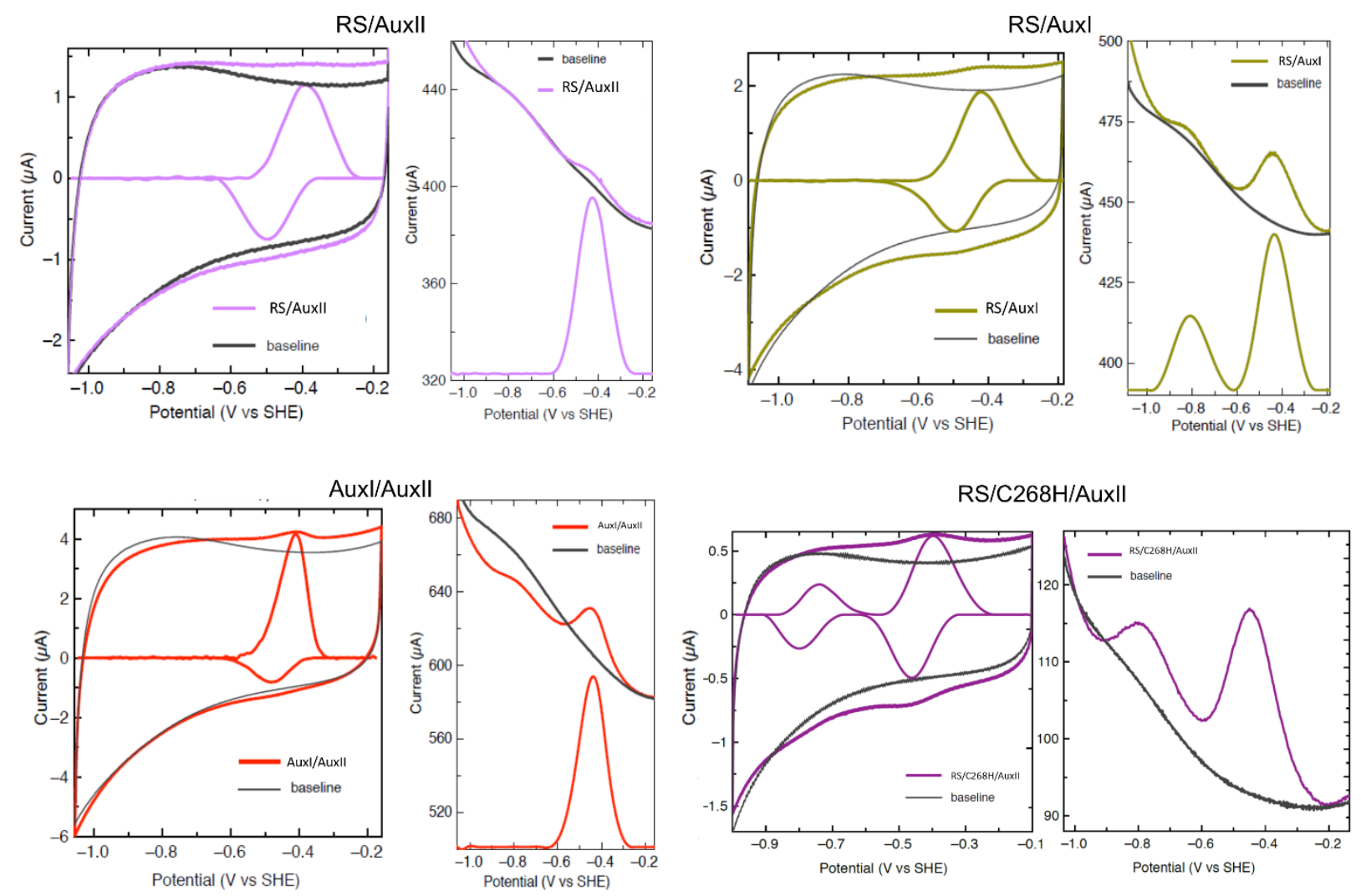

Figure S7 (continued). The electrochemical measurement of WT PqqE and its variants reveal the low potential species. The reduction potential measurements of WT PqqE and its variants. The measurement windows were expanded to $-1.5 \mathrm{~V}$. The colored lines are the measurements for each protein and the black lines are the baseline measurements. For each protein, the cyclic voltammetry measurement is showing on the left and the square wave voltammetry measurement is on the right. 


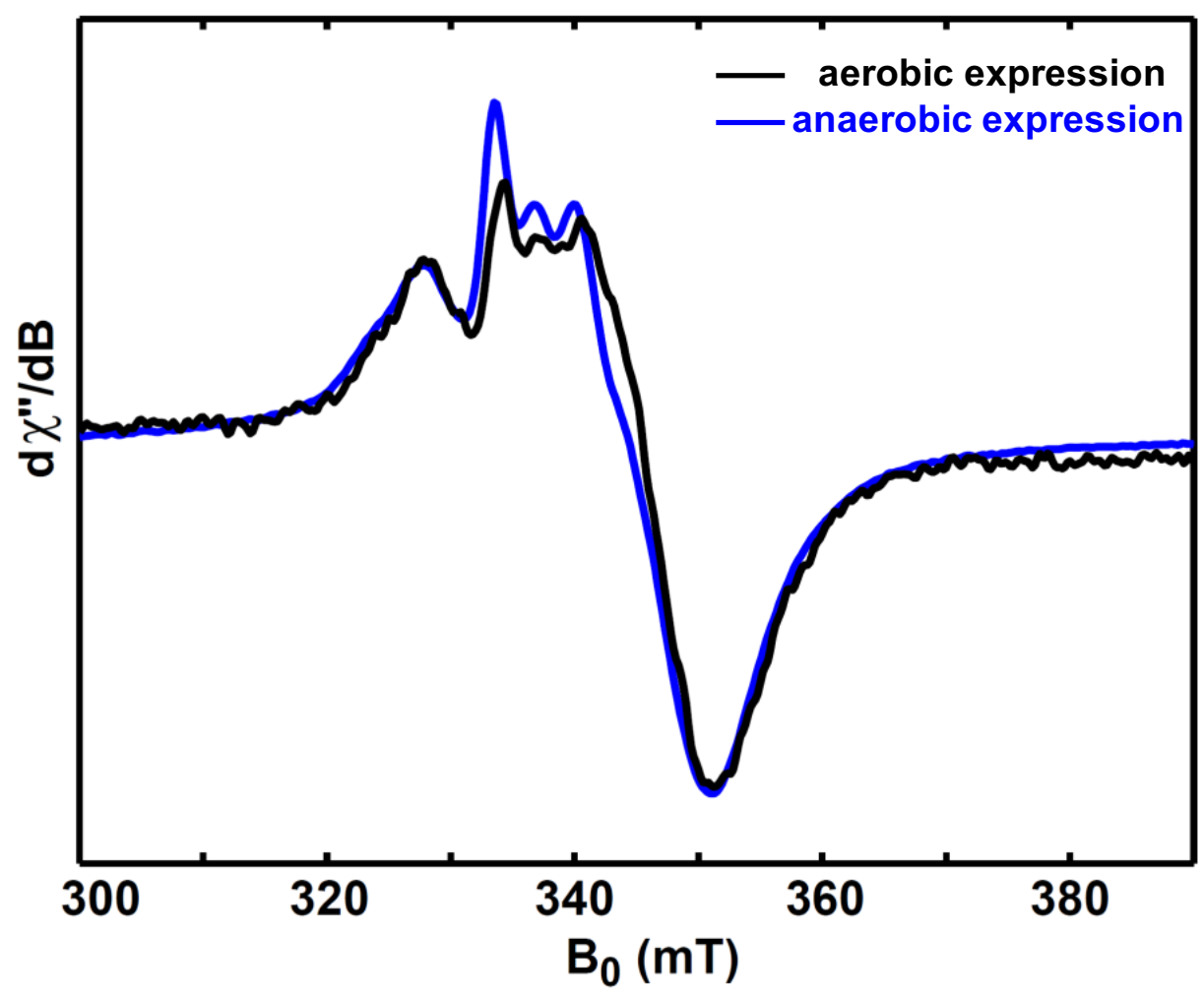

Figure S8. Comparison of X-band $(9.37 \mathrm{GHz})$ CW EPR spectra of dithionite-reduced aseluted strep-tagged wild-type PqqE that was expressed aerobically (black trace) or anaerobically (blue trace). Both protein samples were anaerobically purified. The CW EPR spectra were recorded at $10 \mathrm{~K}$, with $0.02 \mathrm{~mW}$ microwave power (shown to be nonsaturating). 


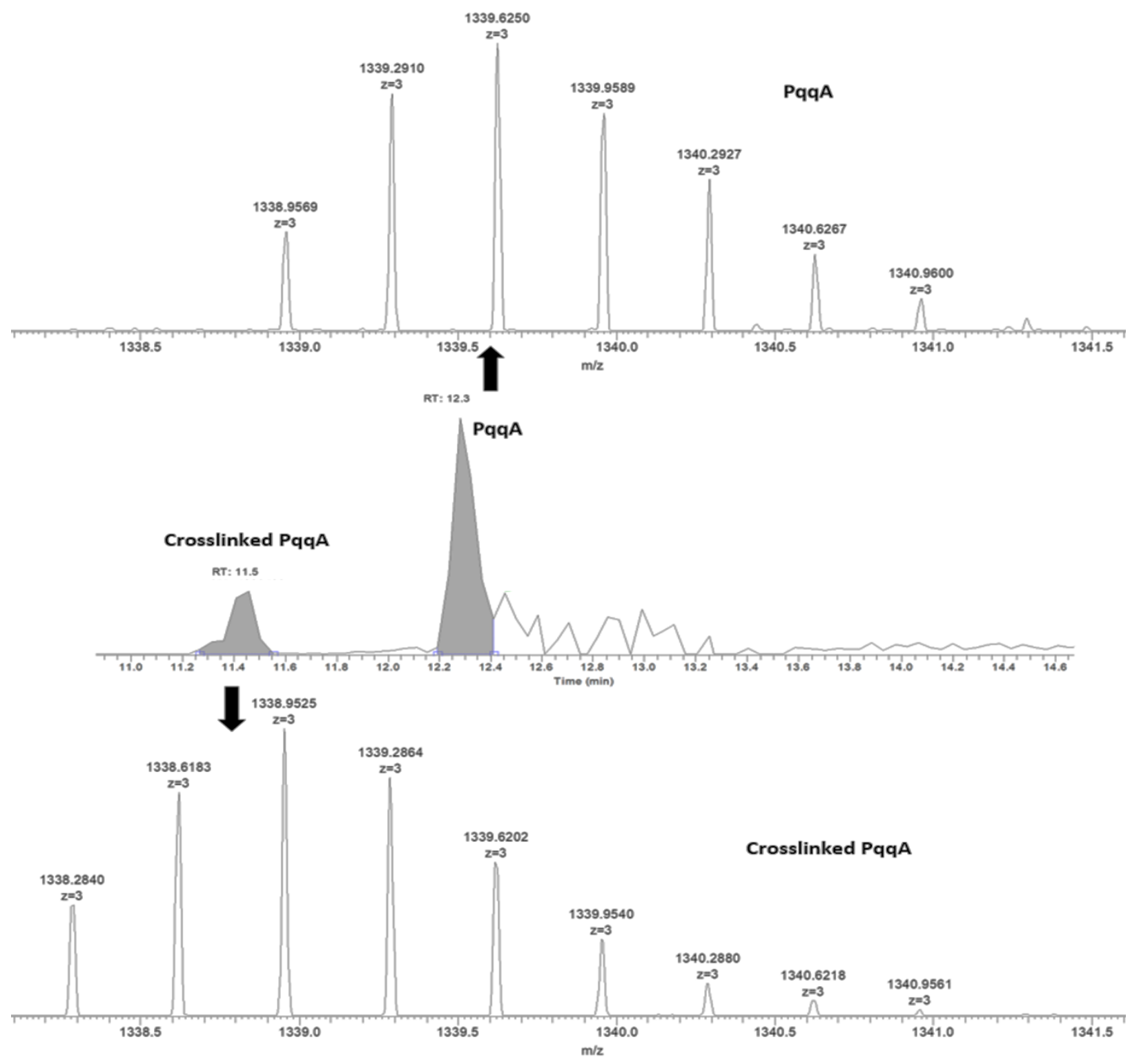

Figure S9. PqqA crosslinked product analysis using high resolution MS. The production of PqqA crosslinked product from the reaction mixture containing PqqE, PqqD, Fd/FNR/NADPH, and SAM was identified and quantified by LC-MS. The LC trace (ion abundance vs. retention time, middle panel) contains residual PqqA (mass spectrum, top panel) and crosslinked PqqA (mass spectrum, bottom panel). 

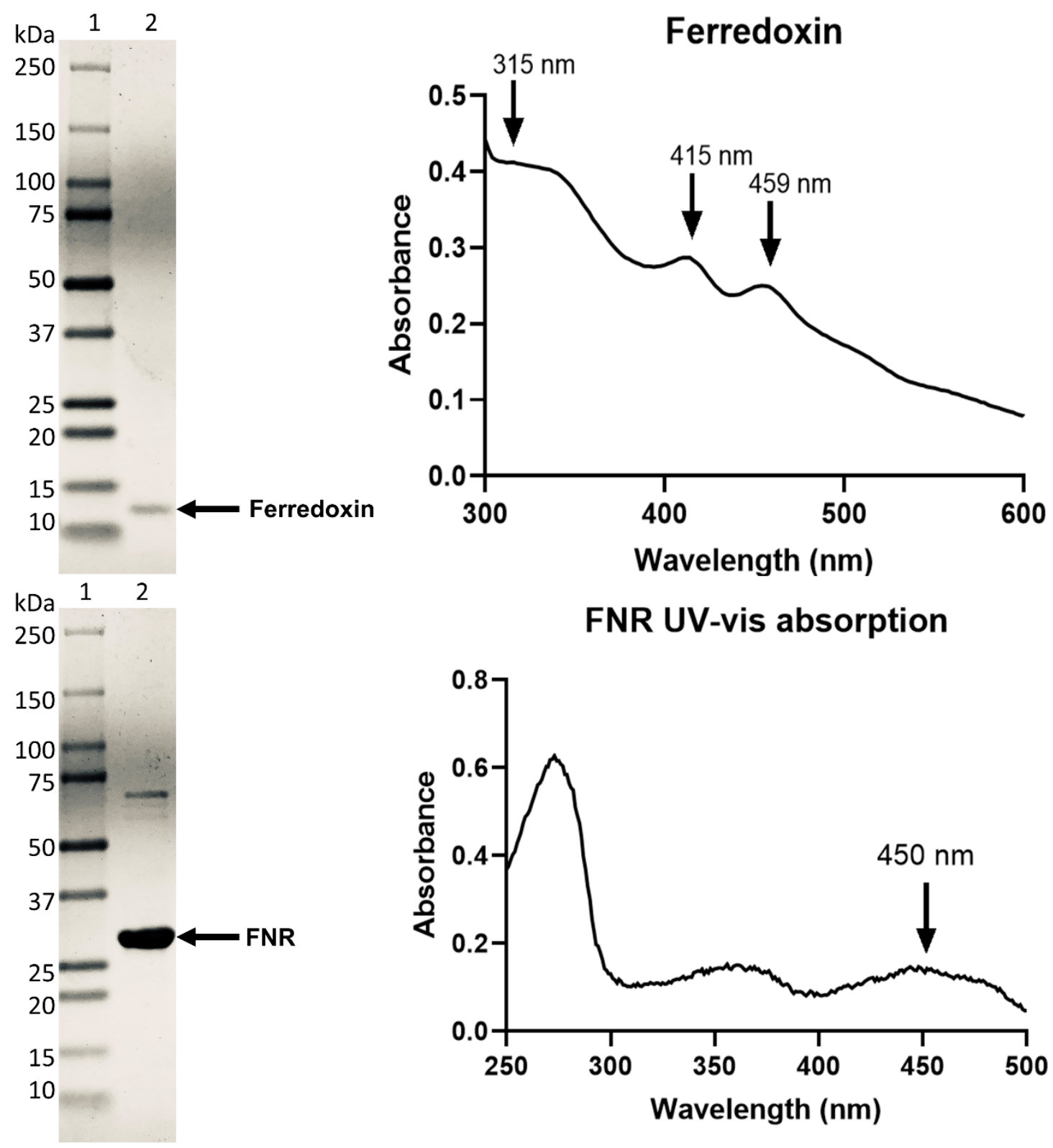

FNR UV-vis absorption

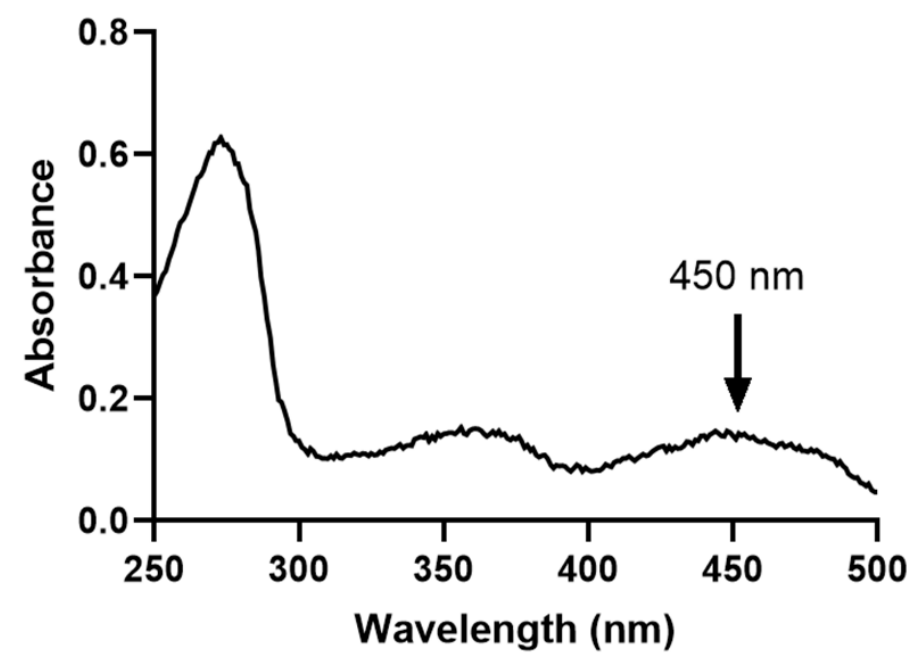

Figure S10. SDS-PAGE and UV-vis spectrum of ferredoxin and ferredoxin-NADP ${ }^{+}$ reductase. Left, the SDS-PAGE of protein marker (lane 1, top and bottom) and ferredoxin (lane 2, top left) and ferredoxin-NADP ${ }^{+}$reductase (FNR) (lane 2, bottom left). Right, UV-vis spectroscopy confirmed that as-purified ferredoxin contains [2Fe-2S] cluster with signature absorption at $315 \mathrm{~nm}, 415 \mathrm{~nm}$ and $459 \mathrm{~nm}$, (top right) and the ferredoxin-NADP ${ }^{+}$reductase contains cofactor FAD with signature wavelength at $450 \mathrm{~nm}$ (bottom right). 

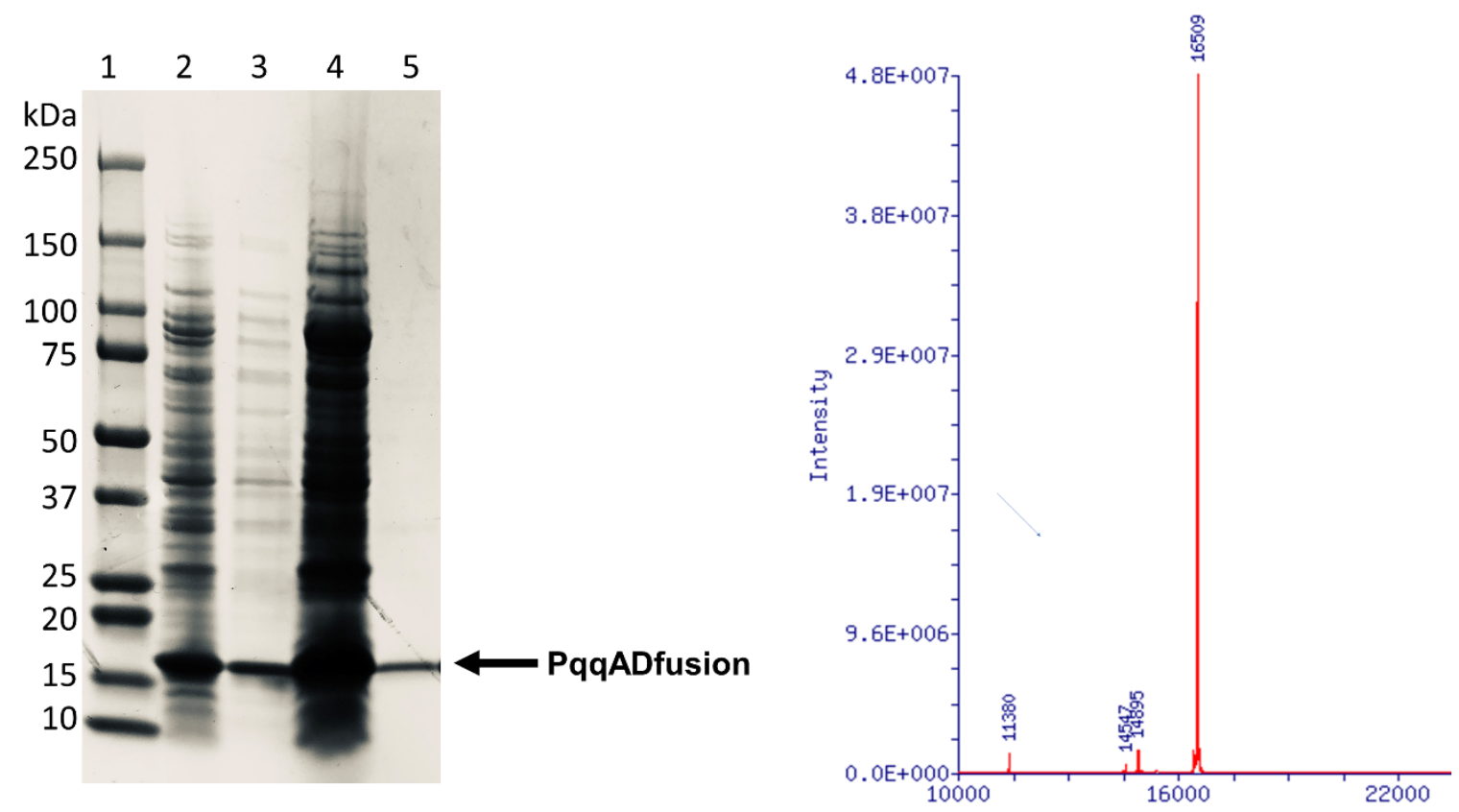

Figure S11. SDS-PAGE and MS analysis confirmed the production of PqqAD fusion protein. The production of full-length PqqAD fusion protein (MW =16509) was confirmed through SDS-PAGE (left) and intact protein MS (right). Left, SDS-PAGE lane 1, protein marker; Lane 2, PqqAD fusion cell lysate; Lane 3, soluble PqqAD fusion cell lysate supernatant; Lane 4, inclusion body of PqqAD fusion cell lysate; Lane 4, purified PqqAD fusion protein. Right, deconvoluted mass spectrum of intact PqqAD fusion protein. 

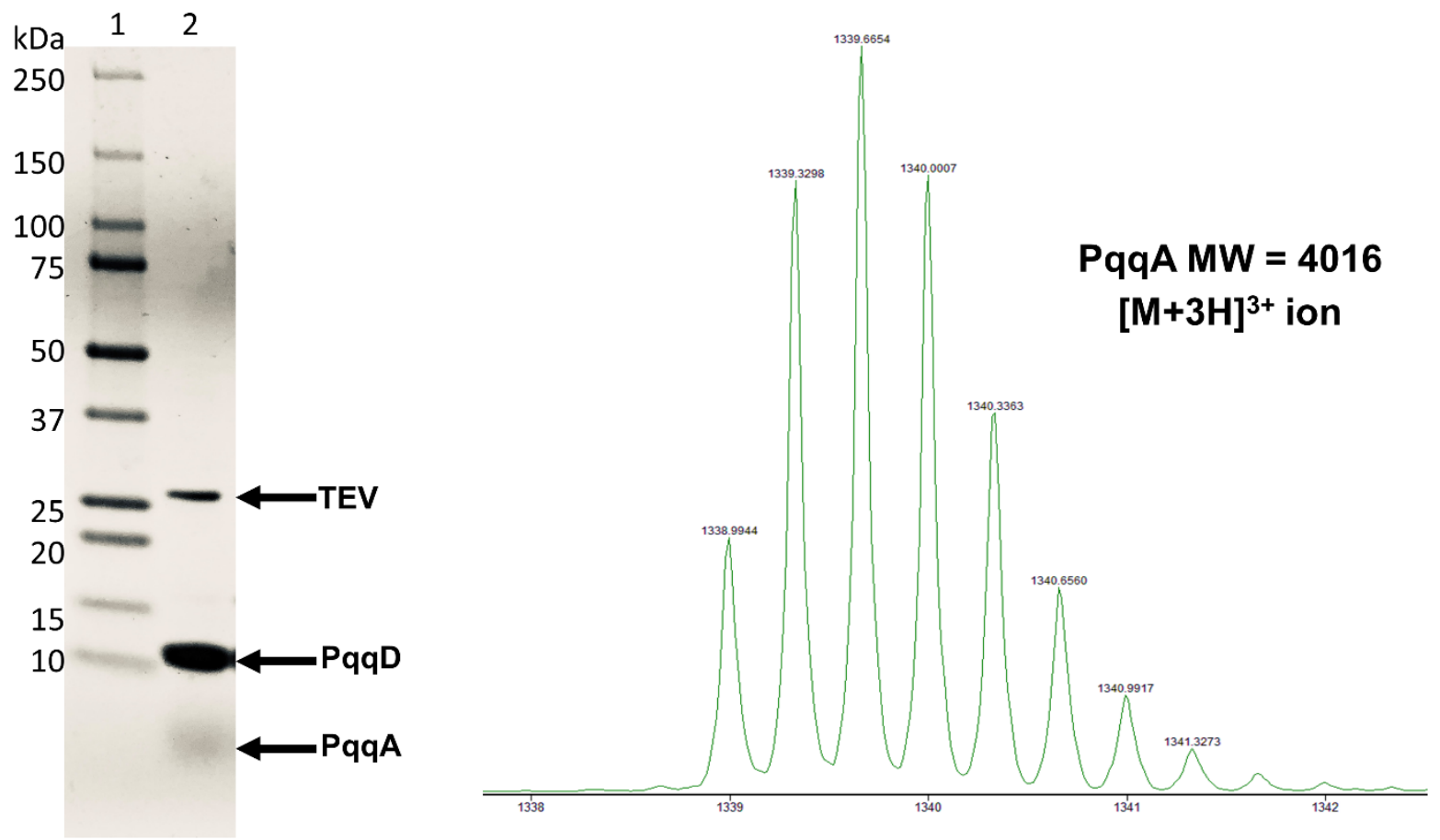

Figure S12. SDS-PAGE and MS analysis confirm the cleavage of PqqA using the PqqAD fusion construct. PqqAD fusion was treated with TEV protease (left, lane 2), and the PqqA/D complex was purified using Ni-NTA column to remove TEV and cleaved His-tag at the Cterminus of PqqD. The PqqA formed from the cleaved PqqAD fusion was confirmed through LC-MS (right). 

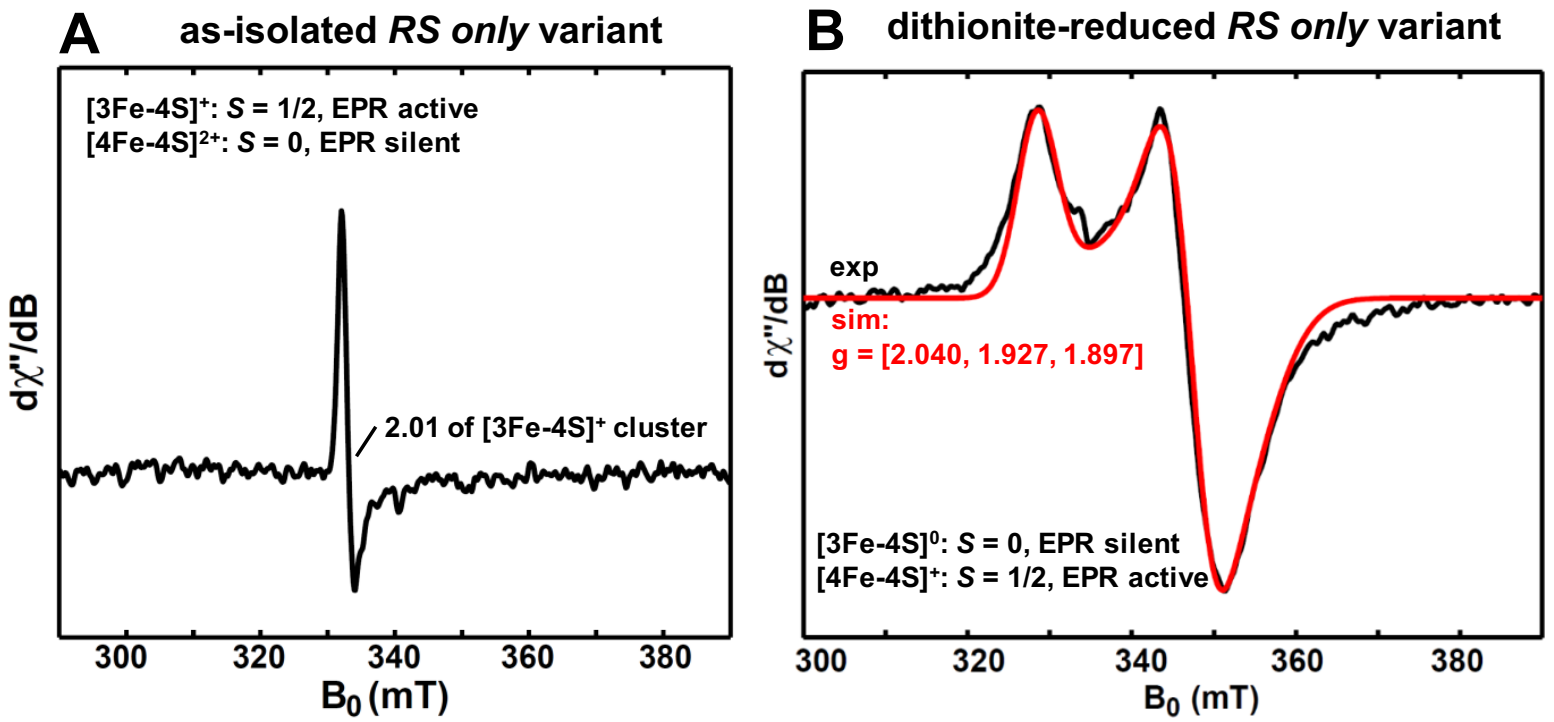

Figure S13. X-band EPR measurement of $\boldsymbol{R S}$ only (A) X-band (9.37 GHz, $15 \mathrm{~K}$ ) CW EPR spectrum of the as-isolated $R S$ only variant (without dithionite), which shows the oxidized [3Fe$4 \mathrm{~S}]^{+}$cluster signal with the RS $[4 \mathrm{Fe}-4 \mathrm{~S}]^{2+}$ cluster being EPR silent. (B) X-band $(9.37 \mathrm{GHz}, 10$ $\mathrm{K}) \mathrm{CW}$ EPR spectrum of dithionite-reduced $R S$ only variant, which shows the reduced RS [4Fe$4 \mathrm{~S}]^{+}$cluster signal with the $[3 \mathrm{Fe}-4 \mathrm{~S}]^{0}$ cluster being EPR silent. 


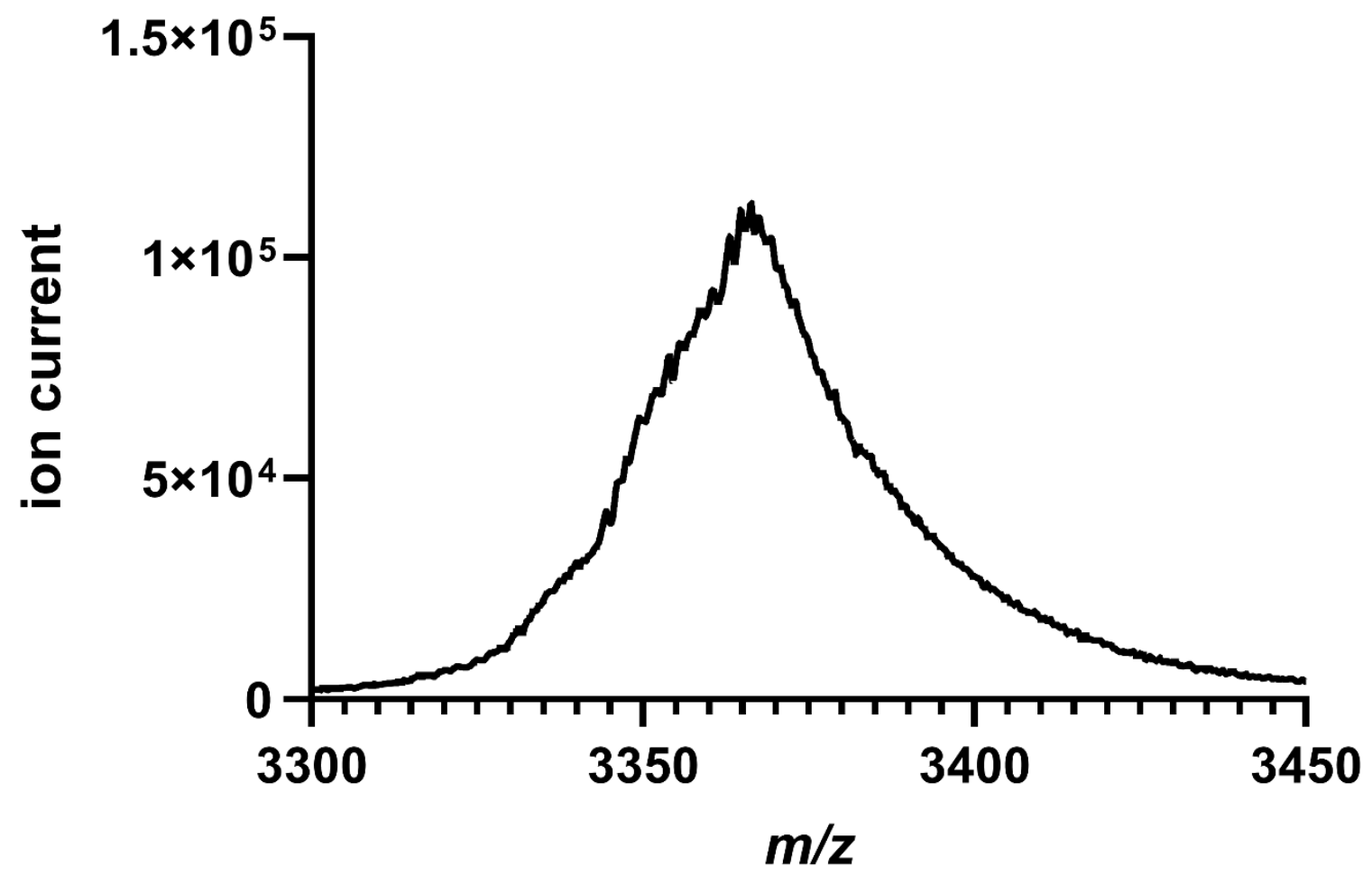

Figure S14. Native MS of $\boldsymbol{R S} / \boldsymbol{C 2 6 8 H} / \mathbf{A u x I I}$. Native mass spectrum of $R S / C 268 H / A u x I I$ lacks well-defined individual species but shows a broad feature containing various species. This suggests complex degradation products formed during the process of measurement, which indicates an unstable protein environment for the occupation of iron-sulfur clusters. 


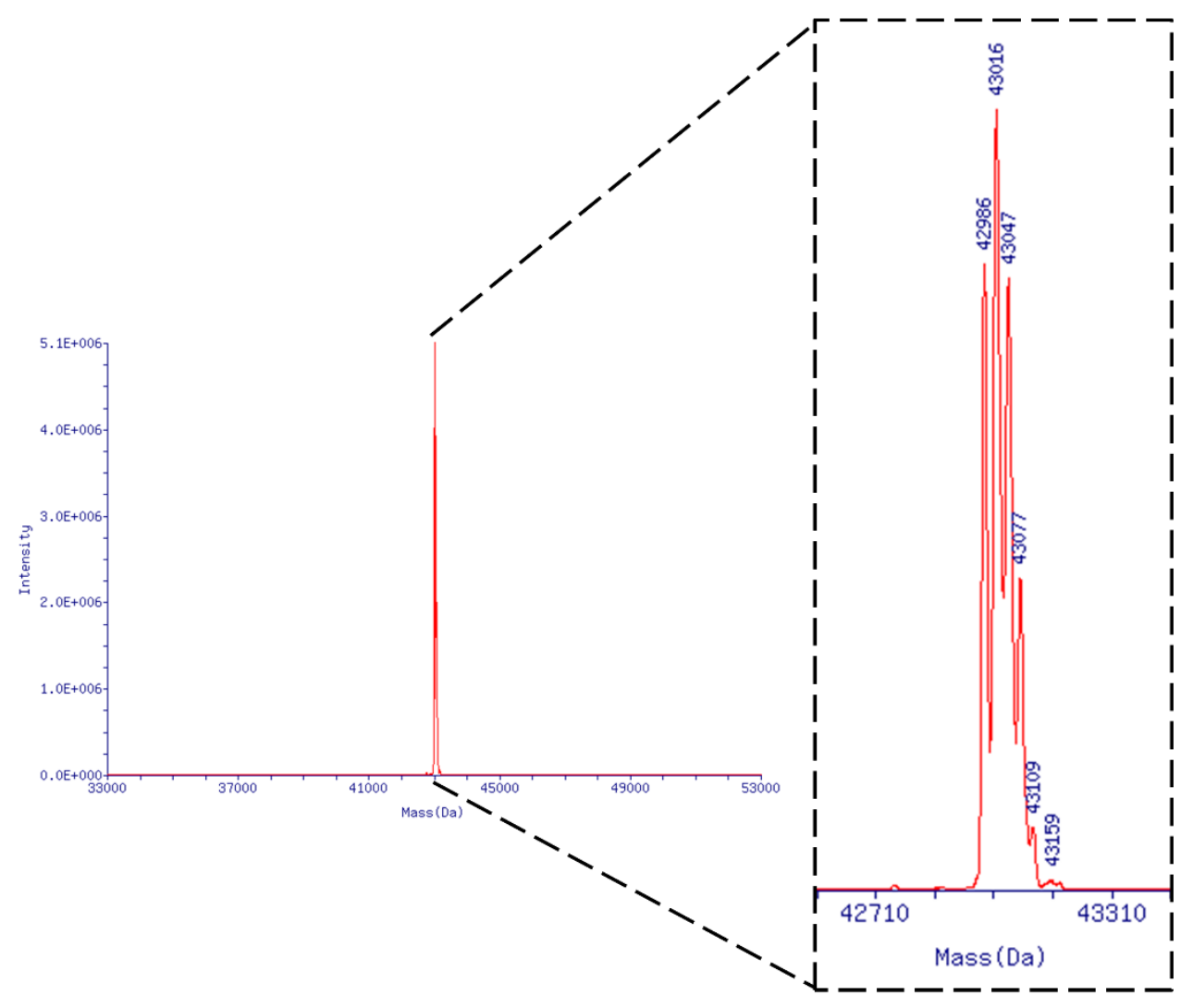

Figure S15. LC-MS of as-purified PqqE. Anaerobically prepared as-purified PqqE was analyzed by LC-MS under typical aerobic conditions. The LC mobile phase solvents contained water, acetonitrile, and formic acid. The calculated MW of apo-PqqE is $42987 \mathrm{Da}$. Besides the apo-form of PqqE (42986 Da), species presumably due to oxidative damage of the iron-sulfur cluster in the as-purified sample are also observed (detail view, inset). The molecular masses of these species are consistent with multiple sulfide adductions on the apo-protein. 
Table S1. Bioinformatic analyses of the iron-sulfur cluster containing proteins that use the CXC motif as ligands in PDB. There are $637 \mathrm{PDB}$ entries containing [2Fe-2S] clusters and 1016 PDB entries containing [4Fe-4S] clusters. The analyses were conducted based on the representative structure with a $90 \%$ sequence identity to avoid redundant sampling. The protein structures were screened individually to make sure that at least one of the cysteines in the CXC motif was a ligand to the iron-sulfur clusters.

\begin{tabular}{|c|c|c|c|c|c|c|}
\hline & PDB ID & CXC & $\begin{array}{c}\text { Number } \\
\text { of Cys in } \\
\text { CXC } \\
\text { binding to } \\
\text { cluster }\end{array}$ & $\begin{array}{c}\text { Two Cys } \\
\text { in CXC } \\
\text { bind to } \\
\text { different } \\
\text { Fe } \\
\end{array}$ & Protein & Organism \\
\hline \multirow{47}{*}{$\begin{array}{c}{[2 \mathrm{Fe}-} \\
2 \mathrm{~S}]\end{array}$} & $6 \mathrm{C} 8 \mathrm{~V}$ & $\mathrm{CRC}$ & 2 & Yes & PqqE & Methylobacterium extorquens \\
\hline & 1DGJ & $\mathrm{CRC}$ & 2 & Yes & Aldehyde oxidoreductase & Desulfovibrio desulfuricans \\
\hline & $1 \mathrm{FFV}$ & $\mathrm{CRC}$ & 2 & Yes & Carbon monoxide dehydrogenase & Hydrogenophaga pseudoflava \\
\hline & $1 \mathrm{JRO}$ & $\mathrm{CRC}$ & 2 & Yes & Xanthine dehydrogenase & Rhodobacter capsulatus \\
\hline & $1 \mathrm{~N} 62$ & $\mathrm{CRC}$ & 2 & Yes & $\mathrm{Mo}, \mathrm{Cu}-\mathrm{CO}$ dehydrogenase (CODH) & Oligotropha carboxidovorans \\
\hline & 1RM6 & $\mathrm{CRC}$ & 2 & Yes & 4-hydroxybenzoyl-CoA reductase & Thauera aromatica \\
\hline & 1T3Q & $\mathrm{CRC}$ & 2 & Yes & Quinoline 2-oxidoreductase & Pseudomonas Putida 86 \\
\hline & $3 \mathrm{AN} 1$ & $\mathrm{CRC}$ & 2 & Yes & Xanthine dehydrogenase & Rattus norvegicus \\
\hline & $3 \mathrm{NVW}$ & $\mathrm{CRC}$ & 2 & Yes & Xanthine oxidase & Bovine \\
\hline & $3 \mathrm{UNC}$ & $\mathrm{CRC}$ & 2 & Yes & Xanthine dehydrogenase & Bos taurus \\
\hline & $3 Z Y V$ & $\mathrm{CRC}$ & 2 & Yes & Aldehyde oxidase 3 & Mus musculus \\
\hline & 4UHW & $\mathrm{CRC}$ & 2 & Yes & Aldehyde oxidase & Homo sapiens \\
\hline & 4USA & $\mathrm{CRC}$ & 2 & Yes & Aldehyde oxidoreductase & Desulfovibrio gigas \\
\hline & 5G5G & CRC & 2 & Yes & Aldehyde oxidase & Escherichia coli \\
\hline & $4 \mathrm{E} 6 \mathrm{~K}$ & CLC & 2 & Yes & Bacterioferritin & Pseudomonas aeruginosa \\
\hline & 2HU9 & $\mathrm{CYC}$ & 2 & Yes & CopZ copper chaperone & Archaeoglobus fulgidus \\
\hline & $6 \mathrm{EFN}$ & $\mathrm{CKC}$ & 2 & Yes & SkfB & Bacillus subtilis \\
\hline & $1 \mathrm{X} 0 \mathrm{G}$ & $\mathrm{CGC}$ & 2 & No & IscA & Thermosynechococcus elongatus \\
\hline & $2 \mathrm{ZHG}$ & CGC & 2 & No & SoxR [2Fe-2S] oxidative-stress sensor & Escherichia coli \\
\hline & $3 \mathrm{FNV}$ & $\mathrm{CRC}$ & 2 & No & Miner1 & Homo sapiens \\
\hline & 3HRD & $\mathrm{CRC}$ & 2 & No & Nicotinate dehydrogenase & Eubacterium barkeri \\
\hline & $3 \mathrm{~S} 2 \mathrm{R}$ & $\mathrm{CRC}$ & 2 & No & ChloroNEET & Arabidopsis thaliana \\
\hline & $3 \mathrm{TBM}$ & $\mathrm{CRC}$ & 2 & No & CDGSH iron-sulfur protein & Ralstonia solanacearum \\
\hline & $3 \mathrm{TBO}$ & $\mathrm{CRC}$ & 2 & No & CDGSH iron-sulfur protein & Pyrobaculum calidifontis \\
\hline & $4 \mathrm{EZF}$ & $\mathrm{CRC}$ & 2 & No & MitoNEET & Homo sapiens \\
\hline & $4 \mathrm{OOA}$ & $\mathrm{CRC}$ & 2 & No & NAF1 & Homo sapiens \\
\hline & $6 \mathrm{AVJ}$ & $\mathrm{CVC}$ & 2 & No & $(\mathrm{MiNT}) / \mathrm{CISD} 3$ & Homo sapiens \\
\hline & $1 \mathrm{E} 9 \mathrm{M}$ & $\mathrm{CAC}$ & 1 & - & Ferredoxin VI & Rhodobacter Capsulatus \\
\hline & $1 \mathrm{I} 7 \mathrm{H}$ & $\mathrm{CAC}$ & 1 & - & Ferredoxin & Escherichia coli \\
\hline & 1JM1 & $\mathrm{CPC}$ & 1 & - & Rieske protein & Sulfolobus acidocaldarius \\
\hline & $1 \mathrm{NYK}$ & $\mathrm{CPC}$ & 1 & - & Rieske protein & $\begin{array}{l}\text { Thermus thermophilus (strain HB8 / ATCC } \\
27634 \text { / DSM 579) }\end{array}$ \\
\hline & $1 \mathrm{Q} 90$ & $\mathrm{CPC}$ & 1 & - & Cytochrome b6f & Chlamydomonas reinhardtii \\
\hline & $1 \mathrm{RFS}$ & $\mathrm{CPC}$ & 1 & - & Rieske protein & Spinacia oleracea \\
\hline & 1RIE & $\mathrm{CPC}$ & 1 & - & Cytochrome bc0 & Bos taurus \\
\hline & 1ZRT & $\mathrm{CPC}$ & 1 & - & Cytochrome bc1 & Rhodobacter capsulatus \\
\hline & $2 \mathrm{~A} 06$ & $\mathrm{CPC}$ & 1 & - & Cytochrome bc1 & Bos taurus \\
\hline & $2 \mathrm{NWF}$ & $\mathrm{CPC}$ & 1 & - & Rieske protein & Rhodobacter sphaeroides \\
\hline & 2QJY & $\mathrm{CPC}$ & 1 & - & Cytochrome bc1 & Rhodobacter sphaeroides \\
\hline & $2 \mathrm{YIU}$ & $\mathrm{CPC}$ & 1 & - & Cytochrome bc1 & Paracoccus denitrificans \\
\hline & $3 \mathrm{AZC}$ & $\mathrm{CPC}$ & 1 & - & Cytochrome b6f & $\begin{array}{c}\text { Thermosynechococcus elongatus (strain } \\
\text { BP-1) }\end{array}$ \\
\hline & $3 \mathrm{CX} 5$ & $\mathrm{CPC}$ & 1 & - & Cytochrome bc1 & $\begin{array}{c}\text { Saccharomyces cerevisiae (strain ATCC } \\
204508 / S 288 \text { c) }\end{array}$ \\
\hline & 3HUI & $\mathrm{CAC}$ & 1 & - & Ferredoxin & Rhodopseudomonas palustris \\
\hline & 4OGQ & $\mathrm{CPC}$ & 1 & - & Cytochrome b6f & $\begin{array}{c}\text { Nostoc sp. (strain PCC } 7120 / S A G 25.82 / \\
\text { UTEX 2576) }\end{array}$ \\
\hline & 4YSX & $\mathrm{CIC}$ & 1 & - & Succinate dehydrogenase & Ascaris suum \\
\hline & $5 \mathrm{CXM}$ & $\mathrm{CPC}$ & 1 & - & Rieske protein & $\begin{array}{c}\text { Synechocystis sp. (strain PCC } 6803 / \\
\text { Kazusa) }\end{array}$ \\
\hline & $5 \mathrm{XMJ}$ & $\mathrm{CGC}$ & 1 & - & Succinate dehydrogenase & Desulfovibrio gigas \\
\hline & $6 \mathrm{HWH}$ & $\mathrm{CPC}$ & 1 & - & $\begin{array}{c}\text { Ubiquinol-cytochrome c reductase iron-sulfur } \\
\text { subunit }\end{array}$ & $\begin{array}{c}\text { Mycobacterium smegmatis (strain ATCC } \\
700084 / m c(2) 155) \\
\end{array}$ \\
\hline
\end{tabular}


Table S1 (continued). Bioinformatic analyses of the iron-sulfur cluster containing proteins that use the CXC motif as ligands in PDB. There are $637 \mathrm{PDB}$ entries containing [2Fe-2S] clusters and 1016 PDB entries containing [4Fe-4S] clusters. The analyses were conducted based on the representative structure with a $90 \%$ sequence identity to avoid redundant sampling. The protein structures were screened individually to make sure that at least one of the cysteines in the CXC motif was a ligand to the iron-sulfur clusters.

\begin{tabular}{|c|c|c|c|c|c|c|}
\hline & PDB ID & $\mathrm{CXC}$ & $\begin{array}{c}\text { Number } \\
\text { of Cys in } \\
\text { CXC } \\
\text { binding to } \\
\text { cluster }\end{array}$ & $\begin{array}{c}\text { Two Cys } \\
\text { in CXC } \\
\text { bind to } \\
\text { different } \\
\text { Fe } \\
\end{array}$ & Protein & Organism \\
\hline \multirow{10}{*}{$\begin{array}{c}{[4 \mathrm{Fe}-} \\
4 \mathrm{~S}]\end{array}$} & 2PU9 & $\mathrm{CHC}$ & 2 & Yes & Ferredoxin-thioredoxin reductase & $\begin{array}{c}\text { Synechocystis sp. (strain PCC 6803/ } \\
\text { Kazusa) }\end{array}$ \\
\hline & 2PU9 & $\mathrm{CPC}$ & 2 & Yes & Ferredoxin-thioredoxin reductase & $\begin{array}{c}\text { Synechocystis sp. (strain PCC 6803/ } \\
\text { Kazusa) }\end{array}$ \\
\hline & 5ODQ & $\mathrm{CHC}$ & 2 & Yes & Heterodisulfide reductase & $\begin{array}{l}\text { Methanothermococcus } \\
\text { thermolithotrophicus }\end{array}$ \\
\hline & $2 \mathrm{H} 88$ & $\mathrm{CAC}$ & 1 & - & Avian Mitochondrial Respiratory Complex II & Gallus gallus \\
\hline & 4YSX & $\mathrm{CGC}$ & 1 & - & $\begin{array}{l}\text { Mitochondrial rhodoquinol-fumarate } \\
\text { reductase }\end{array}$ & Ascaris suum \\
\hline & 2BS2 & CGC & 1 & - & Quinol:fumarate reductase & Wolinella succinogenes \\
\hline & 4TPU & $\mathrm{CPC}$ & 1 & - & Ferredoxin-dependent disulfide reductase & Methanosarcina acetivorans \\
\hline & $5 \mathrm{~T} 5 \mathrm{I}$ & $\mathrm{CPC}$ & 1 & - & $\begin{array}{c}\text { Tungsten formylmethanofuran } \\
\text { dehydrogenase subunit fwdF }\end{array}$ & Methanothermobacter wolfeii \\
\hline & 2Z1D & CRC & 1 & - & {$[\mathrm{NiFe}]$ hydrogenase } & Thermococcus kodakaraensis \\
\hline & $3 \mathrm{CF} 4$ & CYC & 1 & - & Ni-dependent $\mathrm{CO}$ dehydrogenase & Methanosarcina barkeri \\
\hline
\end{tabular}


Table S2. Apparent mid-point reduction potentials for WT PqqE and variants with no deconvolution, using an expanded scanning window.

\begin{tabular}{|c|c|c|c|}
\hline & & Potential 1 & Potential 2 \\
\hline \multirow{2}{*}{$W T$} & cyclic voltammetry & -800 & -475 \\
\hline & squarewave voltammetry & -783 & -455 \\
\hline \multirow{2}{*}{ RS only } & cyclic voltammetry & -785 & -465 \\
\hline & squarewave voltammetry & -785 & -435 \\
\hline \multirow{2}{*}{ AuxI only } & cyclic voltammetry & & -435 \\
\hline & squarewave voltammetry & & -395 \\
\hline \multirow{2}{*}{$R S / A u x I / D 319 H$} & cyclic voltammetry & -800 & -465 \\
\hline & squarewave voltammetry & -790 & -445 \\
\hline \multirow{2}{*}{$R S / A u x I / D 319 C$} & cyclic voltammetry & & -475 \\
\hline & squarewave voltammetry & & -483 \\
\hline \multirow{2}{*}{$R S / D 319 C$} & cyclic voltammetry & & -460 \\
\hline & squarewave voltammetry & & -450 \\
\hline \multirow{2}{*}{$R S / A u x I I$} & cyclic voltammetry & & -470 \\
\hline & squarewave voltammetry & & -455 \\
\hline \multirow{2}{*}{$R S / A u x I$} & cyclic voltammetry & -810 & -460 \\
\hline & squarewave voltammetry & -805 & -435 \\
\hline \multirow{2}{*}{ AuxI/AuxII } & cyclic voltammetry & & -475 \\
\hline & squarewave voltammetry & & -465 \\
\hline \multirow{2}{*}{$R S / C 268 H / A u x I I$} & cyclic voltammetry & -800 & -450 \\
\hline & squarewave voltammetry & -790 & -450 \\
\hline
\end{tabular}


Table S3. Primers used in this study.

\begin{tabular}{|c|c|c|}
\hline & Primer & Sequence \\
\hline 1 & C28A forward & 5'- GTT AAC GCA CCG TGC TCC ATT GCG TTG C -3' \\
\hline 2 & C28A reverse & 5'- GCA ACG CAA TGG AGC ACG GTG CGT TAA C -3' \\
\hline 3 & $\begin{array}{c}\mathrm{C} 28 \mathrm{~A} / \mathrm{C} 32 \mathrm{~A} / \mathrm{C} 35 \mathrm{~A} \\
\text { forward }\end{array}$ & 5'- CAC CGT GCT CCA TTG CGT GCC CCT TAT GCT AGT AAT C -3' \\
\hline 4 & $\mathrm{C} 28 \mathrm{~A} / \mathrm{C} 32 \mathrm{~A} / \mathrm{C} 35 \mathrm{~A}$ reverse & 5'- GAT TAC TAG CAT AAG GGG CAC GCA ATG GAG CAC GGT G -3' \\
\hline 5 & $\begin{array}{c}\mathrm{C} 28 \mathrm{~A} / \mathrm{C} 32 \mathrm{~A} / \mathrm{C} 35 \mathrm{~A} / \mathrm{D} 319 \mathrm{H} \\
\text { forward }\end{array}$ & 5'- GAT CGT CGT GAG AAA CAT TGG GGG GGA TGT C -3' \\
\hline 6 & $\begin{array}{c}\mathrm{C} 28 \mathrm{~A} / \mathrm{C} 32 \mathrm{~A} / \mathrm{C} 35 \mathrm{~A} / \mathrm{D} 319 \mathrm{H} \\
\text { reverse }\end{array}$ & 5'- GAC ATC CCC CCC AAT GTT TCT CAC GAC GAT C -3' \\
\hline 7 & $\begin{array}{l}\mathrm{C} 28 \mathrm{~A} / \mathrm{C} 32 \mathrm{~A} / \mathrm{C} 35 \mathrm{~A} / \mathrm{D} 319 \mathrm{C} \\
\text { forward }\end{array}$ & 5'- GAT CGT CGT GAG AAA TGT TGG GGG GGA TGT C -3' \\
\hline 8 & $\begin{array}{c}\mathrm{C} 28 \mathrm{~A} / \mathrm{C} 32 \mathrm{~A} / \mathrm{C} 35 \mathrm{~A} / \mathrm{D} 319 \mathrm{C} \\
\text { reverse }\end{array}$ & 5'- GAC ATC CCC CCC AAC ATT TCT CAC GAC GAT C -3' \\
\hline 9 & C310A forward & 5'- GAT GAA GGA GCC AGC TCG CTC CTG TGA TCG -3' \\
\hline 10 & C310A reverse & 5'- CGA TCA CAG GAG CGA GCT GGC TCC TTC ATC -3' \\
\hline 11 & $\mathrm{C} 310 \mathrm{~A} / \mathrm{C} 313 \mathrm{~A}$ forward & 5'- GCC AGC TCG CTC CGC TGA TCG TCG TGA G -3' \\
\hline 12 & $\mathrm{C} 310 \mathrm{~A} / \mathrm{C} 313 \mathrm{~A}$ reverse & 5'- CTC ACG ACG ATC AGC GGA GCG AGC TGG C -3' \\
\hline 13 & C268A forward & 5'- GGA AAG TCT TAC CTG CCC ACG CTG CTG AGA C -3' \\
\hline 14 & C268A reverse & 5'- GTC TCA GCA GCG TGG GCA GGT AAG ACT TTC C -3' \\
\hline 15 & C248A/C268A forward & 5'- CAA ATA TCC TAA GGC GTG GCC GGG CGG TTG G -3' \\
\hline 16 & $\mathrm{C} 248 \mathrm{~A} / \mathrm{C} 268 \mathrm{~A}$ reverse & 5'- CCA ACC GCC CGG CCA CGC CTT AGG ATA TTT G -3' \\
\hline 17 & $\begin{array}{c}\mathrm{C} 310 \mathrm{~A} / \mathrm{C} 313 \mathrm{~A} / \mathrm{C} 323 \mathrm{~A} \\
\text { forward }\end{array}$ & 5'- GAT TGG GGG GGA GCT CGC TGT CAA G -3' \\
\hline 18 & $\begin{array}{c}\mathrm{C} 310 \mathrm{~A} / \mathrm{C} 313 \mathrm{~A} / \mathrm{C} 323 \mathrm{~A} \\
\text { reverse }\end{array}$ & 5'- CTT GAC AGC GAG CTC CCC CCC AAT C -3' \\
\hline 19 & $\begin{array}{l}\mathrm{C} 310 \mathrm{~A} / \mathrm{C} 313 \mathrm{~A} / \mathrm{C} 323 \mathrm{~A} \\
/ \mathrm{C} 325 \mathrm{~A} \text { forward }\end{array}$ & 5'- GGG AGC TCG CGC TCA AGC ATT GGC CTT AAC -3' \\
\hline 20 & $\begin{array}{c}\mathrm{C} 310 \mathrm{~A} / \mathrm{C} 313 \mathrm{~A} / \mathrm{C} 323 \mathrm{~A} \\
\text { /C325A reverse }\end{array}$ & AG GCC AAT GCT TGA GCG CGA GCT CCC -3' \\
\hline 21 & $\mathrm{C} 268 \mathrm{H}$ forward & 5'- GGG AAA GTC TTA CCT CAC CAC GCT GCT GAG ACG -3' \\
\hline 22 & $\mathrm{C} 268 \mathrm{H}$ reverse & GC AGC GTG GTG AGG TA \\
\hline
\end{tabular}


Table S4. Iron and sulfur content of PqqE and variants.

\begin{tabular}{|c|c|c|}
\hline & $\mathrm{Fe}$ & $\mathrm{S}$ \\
\hline WT & $10 \pm 1$ & $11 \pm 1$ \\
\hline WT reconstituted & $12 \pm 1$ & $13 \pm 1$ \\
\hline RS only & $4 \pm 1$ & $4 \pm 1$ \\
\hline AuxI only & $0.5 \pm 1$ & $0.2 \pm 1$ \\
\hline RS/AuxI/D319H & $10 \pm 1$ & $13 \pm 2$ \\
\hline$R S /$ AuxI/D319C & $13 \pm 2$ & $13 \pm 1$ \\
\hline$R S / D 319 C$ & $8 \pm 1$ & $8 \pm 1$ \\
\hline$R S /$ AuxI & $9 \pm 2$ & $8 \pm 2$ \\
\hline$R S /$ AuxII & $6 \pm 1$ & $5 \pm 2$ \\
\hline AuxI/AuxII & $6 \pm 1$ & $5 \pm 2$ \\
\hline$R S / C 268 H /$ AuxII & $9 \pm 1$ & $10 \pm 1$ \\
\hline
\end{tabular}


DNA sequences used in this study. The underlined bases indicate the restriction enzyme digest sites.

\section{Codon optimized N-terminal strep-tagged PqqE DNA sequence}

\begin{tabular}{|c|c|c|c|c|}
\hline & & & AAAAGGGTGC & AATGAATGCC \\
\hline CCTACGCCTG & СТССТTСАСС & CGTCGACGTT & ATCCCAGCAC & CCGTAGGGTT \\
\hline ATTGGCTGAG & TTAACGCACC & GTTGTCCATT & GCGTTGCCCT & TATTGCAGTA \\
\hline ATCCACTGGA & ATTGGACCGT & CGCTCAGCAG & AACTGGACAC & ACAGACGTGG \\
\hline TTGCGCGTCC & TTACCGAAGC & TGCTGGGTTG & GGAGTGTTGC & ATGTTCACCT \\
\hline GTCCGGCGGG & GAGCCAACCG & CGCGTCCCGA & CATTGTTGAA & ATCACTGCCA \\
\hline AGTGTGCAGA & GCTTGGTTTG & ATAGTAATC & TTATCACСТC & TGGCGTGGGA \\
\hline GGGGCGCTTG & CCAAGCTTGA & TGCCTTATAT & GATGTTGGTC & TTGATCACGT \\
\hline CCAATTAAGT & GTACAGGGAG & TCGACGCTGC & TAACGCCGAA & AAAATCGGTG \\
\hline GGCTGAAGAA & TGCGCAGCCG & CAGAAAATGC & AATTTGCTGC & CCGTGTAACC \\
\hline GAACTGGGAT & TACCATTGAC & GTTAAATTCT & GTAATTCATC & GTGGTAATAT \\
\hline TCACGAGGTC & CCGGGATTTA & TTGATTTGGC & TGTCAAACTT & GGAGCGAAAC \\
\hline GCCTGGAGGT & AGCTCATACT & CAGTATTATG & GTTGGGCGTA & TGTCAATCGC \\
\hline GCTGCATTAA & TGCCCGACAA & GTCACAGGTA & GACGAGAGCA & TCCGCATCGT \\
\hline AGAGGCTGCC & CGCGAACGCC & TGAAAGGGCA & GCTGGTGATC & GACCTGGTGG \\
\hline TGCCGGACTA & CTATGCCAAA & TATCCTAAGG & CGTGTGCGGG & CGGTTGGGGA \\
\hline CGCAAACTTA & TGAACGTCAC & CCCGCAAGGG & AAAGTCTTAC & CTTGCCACGC \\
\hline TGCTGAGACG & ATCCCCGGTT & TAGAATTCTG & GTATGTGACC & GACCACGCTT \\
\hline TAGGAGAGAT & TTGGACCAAA & TCTCCAGCCT & TCGCGGCTTA & TCGCGGGACC \\
\hline TCATGGATGA & AGGAGCCATG & TCGCTCCTGT & GATCGTCGTG & AGAAAGATTG \\
\hline GGGGGGATGT & CGCTGTCAAG & САTTGGCCTT & AACAGGCGAT & GCCGCCAACA \\
\hline CCGACCCTGC & стGCTCTCTG & AGCCCCCTTC & ATGCCAAGAT & GCGTGACCTT \\
\hline GCGAAAGA & AAGCTGCCGA & CACCGCCT & GATTACATTT & ACCGCTCTAT \\
\hline TGGGACTAAT & & & & TTGTGACTCG \\
\hline
\end{tabular}

Codon-optimized N-terminal strep-tagged Ferredoxin DNA sequence

\begin{tabular}{|c|c|c|c|c|}
\hline & & & & \\
\hline $\begin{array}{l}\text { AIIACATICG } \\
\text { CGGCAGCACA }\end{array}$ & IGGACLACGL & AGGAACAGLA & CGTACAAT & IGGLGAA \\
\hline CGGCAGCACA & GTCATGGAAA & CGGCGATTCG & CAACAACGTT & $C G G \perp A \perp \perp$ \\
\hline ATGCCGAATG & GGGCA & TGTGCTTGCG & CGACATGCCA & TTCT \\
\hline TGGAGAGT & GGGCTGACAA & GGTTGGCCCT & GCTGAACCAA & TGG \\
\hline TTGTTGGAC & TTTGCCAGCG & ATGTGCGTGC & CACCTCACGC & CTGTGT \\
\hline AATTCGCGT & САСТCCTGAG & CTTGACGGCT & TAATCGTTAC & $\mathrm{CACC}$ \\
\hline & & & & \\
\hline
\end{tabular}

\section{Codon-optimized N-terminal His-tagged ferredoxin-NADP ${ }^{+}$reductase DNA sequence}

\begin{tabular}{lllll} 
CATATGTCCA & AGTACAACGA & GGAACGTGTA & CTTTCAGTCC & ACCACTGGAC \\
\hline TGATACACTT & TTCAGCTTCC & GCACAACGCG & TGATCCCTCG & TTCCGTTTCC \\
GCAATGGAGA & ATTCACTATG ATCGGGATTG & AGGTGGAGGG & ACGCCCCTTG \\
TTACGCGCT & ATAGTGTTG & GTCTGCGAAT & TACGAAGA & AACTTGAGTT \\
TTTTAGCATT & AAAGTCCCTA & ACGGGCCCCT & TACCTCCAAG & TTGCAGCATC
\end{tabular}




\begin{abstract}
tgAAggtCGg tgAtCCAAtT AtgAttgggA AAAAACCAAC tgGgACCCtg GTTTTAGATA ATTTATTGCC GGgtAAGAAT TTATATCTTC TGGGGACGGG GACCGGATTA GCACCCTTCC TTTCCATCAT CAAAGATCCG GAAACCTATG ACCGCTTTGA AAAgGTAgTt TTGgTGCACG GGTGTCGCCA GgTCCAGGAG CTTGCCTATG GAGAGACTAT CACGGAGACT TTGCCAAAAC ATGAATTTCT GGGCGAGATG ATTGCGAACC AGCTTATTTA TTACCCGACT GTTACCCGCG AACCTTTCCG TAACCGTGgG CGTATCACAg ATTTGATGAC ATCAGgAAAA TtAtTtgaAg AtAtCGgACT GCCGAAtATg AgtATCGAAA ACGATCGTtT tATgCtTtgC GgtAgtCCGg AgAtgAttAA AGAtACGCGT GAAATGCTGA CTGGTCTGGg CTACGAGGAg GgGAATCATG GAGAAGCTGC ACACTACGTG ATTGAAAAAg CGTTTGTCGA AAAATGACTC GAG
\end{abstract}

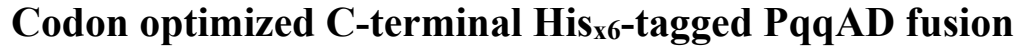

\begin{tabular}{|c|c|c|c|c|}
\hline & & & & \\
\hline$\overline{\text { GGTCACGAGT }}$ & TATGAAAGCG & CTGAGATTGA & TACATTTAAC & CTTT \\
\hline АСТTССААТС & TGAGCCAACT & GCATTTTCGG & GAAGCGATGT & \\
\hline CCACGTGGTG & GTTTACG & CTTTGATGAA & GTAATA & D1 \\
\hline GCTTGCACCT & GAACGTACCT & TTGATTTAGA & CGATAATGCT & $\mathrm{A}$ \\
\hline TAAAGCTGGT & AGACGGGCGC & AACACCGTTT & CGCAGATCGC & $\mathrm{ATC}$ \\
\hline GGGCAAACTT & TGCGGA & CCCGCCATC & TCGAAGCAG & \\
\hline TATGCI & $G^{\prime}$ & CGCGT & GCTTGAACGC & ( \\
\hline TTTE & & & & \\
\hline
\end{tabular}




\section{Protein sequences used in this study.}

N-terminal strep-tagged PqqE protein sequence. The first methionine processed by the methionine aminopeptidase in E. coli during expression is shown in red.

MASWSHPQFEKGAMNAPTPAPSPVDVIPAPVGLLAELTHRCPLRCPYCSNPLELDRRSAELDTQ TWLRVLTEAAGLGVLHVHLSGGEPTARPDIVEITAKCAELGLYSNLITSGVGGALAKLDALYDV GLDHVQLSVQGVDAANAEKIGGLKNAQPQKMQFAARVTELGLPLTLNSVI HRGNI HEVPGFIDL AVKLGAKRLEVAHTQYYGWAYVNRAALMPDKSQVDES IRIVEAARERLKGQLVIDLVVPDYYAK YPKACAGGWGRKLMNVTPQGKVLPCHAAET I PGLEFWYVTDHALGEIWTKSPAFAAYRGTSWMK EPCRSCDRREKDWGGCRCQALALTGDAANTDPACSLSPLHAKMRDLAKEEAAETPPDYIYRS IG TNVQNPLSEKAPL

\section{N-terminal strep-tagged Ferredoxin protein sequence}

MASWSHPQFEKGAMPKITFVDHAGTARTIDGEVGSTVMETAIRNNVPGIDAECGGACACATCHV YVDGEWADKVGPAE PMEQDMLDFASDVRATSRLCCQIRVTPELDGLIVTTPARQG

\section{N-terminal His-tagged ferredoxin-NADP ${ }^{+}$reductase protein sequence}

MGSSHHHHHHSSGLVPRGSHMSKYNEERVLSVHHWTDTLFSFRTTRDPSFRFRNGEFTMIGIEV EGRPLLRAYSVVSANYEEELEFFS IKVPNGPLTSKLQHLKVGDP IMIGKKPTGTLVLDNLLPGK NLYLLGTGTGLAPFLS I IKDPETYDRFEKVVLVHGCRQVQELAYGETITETLPKHEFLGEMIAN QLIYYPTVTREPFRNRGRITDLMTSGKLFEDIGLPNMS IENDRFMLCGSPEMIKDTREMLTGLG YEEGNHGEAAHYVIEKAFVEK

\section{PqqAD fusion protein sequence}

MKWAAPIVSEICVGMEVTSYESAEIDTFNENLYFQSEPTAFSGSDVPRLPRGVRLRFDEVRNKH VLLAPERTFDLDDNAVAVLKLVDGRNTVSQIAQI LGQTYDADPA I IEADI LPMLAGLAQKRVLE RAGENLYFQSALEHHHHHH 


\section{Supporting References}

(1) Zhu, W.; Martins, A. M.; Klinman, J. P. Chapter fourteen Methods for expression, purification, and characterization of PqqE, a radical SAM enzyme in the PQQ biosynthetic pathway. Methods Enzymol. 2018, 606, 389-420.

(2) Grove, T. L.; Ahlum, J. H.; Sharma, P.; Krebs, C.; Booker, S. J. A consensus mechanism for radical SAM-dependent dehydrogenation? BtrN contains two [4Fe-4S] clusters. Biochemistry 2010, 49 (18), 3783-3785.

(3) Liu, T. Y.; Iavarone, A. T.; Doudna, J. A. RNA and DNA targeting by a reconstituted Thermus thermophilus type III-A CRISPR-Cas system. PLoS One 2017, 12 (1), e0170552.

(4) Fourmond, V. QSoas: a versatile software for data analysis. Anal. Chem. 2016, 88 (10), 5050-5052.

(5) Zehnder, A. J.; Wuhrmann, K. Titanium (III) citrate as a nontoxic oxidation-reduction buffering system for the culture of obligate anaerobes. Science 1976, 194 (4270), 1165-1166.

(6) Barr, I.; Stich, T. A.; Gizzi, A. S.; Grove, T. L.; Bonanno, J. B.; Latham, J. A.; Chung, T.; Wilmot, C. M.; Britt, R.; Almo, S. C.; Klinman, J. P. X-Ray and EPR characterization of the auxiliary Fe-S clusters in the radical SAM enzyme PqqE. Biochemistry 2018, 57 (8), 1306-1315.

(7) Tao, L.; Zhu, W.; Klinman, J. P.; Britt, D. R. Electron paramagnetic resonance Spectroscopic identification of the Fe-S clusters in the SPASM domain-containing radical SAM enzyme PqqE. Biochemistry 2019, 58 (51), 5173-5187.

(8) Johnson, K. A.; Verhagen, M. F.; Brereton, P. S.; Adams, M. W.; \& Amster, I. J. Probing the stoichiometry and oxidation states of metal centers in iron- sulfur proteins using electrospray FTICR mass spectrometry. Anal. Chem. 2000, 72 (7), 1410-1418.

(9) Flick, T. G.; Merenbloom, S. I.; \& Williams, E. R. Effects of metal ion adduction on the gasphase conformations of protein ions. J. Am. Soc. Mass. Spec. 2013, 24 (11), 1654-1662.

(10) Lin, C. W.; McCabe, J. W.; Russell, D. H.; \& Barondeau, D. P. Molecular mechanism of ISC iron-sulfur cluster biogenesis revealed by high-resolution native mass spectrometry. J. Am. Chem. Soc. 2020, 142 (13), 6018-6029.

(11) Arragain, S.; Bimai, O.; Legrand, P.; Caillat, S.; Ravanat, J.L.; Touati, N.; Binet, L.; Atta, M.; Fontecave, M.; \& Golinelli-Pimpaneau, B. Nonredox thiolation in tRNA occurring via sulfur activation by a [4Fe-4S] cluster. Proc. Natl. Acad. Sci. 2017, 114, 7355-7360.

(12) Busch, J. L.; Breton, J. L.; Bartlett, B. M.; Armstrong, F. A.; James, R.; and Thomson, A. J.[3Fe-4S] $\leftrightarrow[4 \mathrm{Fe}-4 \mathrm{~S}]$ cluster interconversion in Desulfovibrio africanus ferredoxin III:

properties of an Asp14 $\rightarrow$ Cys mutant. Biochem. J. 1997, 323, 95-102.

(13) Maiocco, S. J.; Grove, T. L.; Booker, S. J.; Elliott, S. J. Electrochemical resolution of the [4Fe-4S] centers of the AdoMet radical enzyme BtrN: Evidence of proton coupling and an unusual, low-potential auxiliary cluster. J. Am. Chem. Soc. 2015, 137, 8664-8667. 